\title{
A Dislocation-Based Theory for the Deformation Hardening Behavior of DP Steels: Impact of Martensite Content and Ferrite Grain Size
}

\author{
Yngve Bergström, ${ }^{1}$ Ylva Granbom, ${ }^{2}$ and Dirk Sterkenburg ${ }^{1}$ \\ ${ }^{1}$ YB Materialteknik, Knäppgatu 12, 78395 Gustafs, Sweden \\ ${ }^{2}$ Product Development/Materials Research, SSAB, 78184 Borlänge, Sweden \\ Correspondence should be addressed to Ylva Granbom, ylva.granbom@ssab.com
}

Received 30 April 2010; Revised 25 August 2010; Accepted 22 October 2010

Academic Editor: Yuri Estrin

Copyright (C) 2010 Yngve Bergström et al. This is an open access article distributed under the Creative Commons Attribution License, which permits unrestricted use, distribution, and reproduction in any medium, provided the original work is properly cited.

\begin{abstract}
A dislocation model, accurately describing the uniaxial plastic stress-strain behavior of dual phase (DP) steels, is proposed and the impact of martensite content and ferrite grain size in four commercially produced DP steels is analyzed. It is assumed that the plastic deformation process is localized to the ferrite. This is taken into account by introducing a nonhomogeneity parameter, $f(\varepsilon)$, that specifies the volume fraction of ferrite taking active part in the plastic deformation process. It is found that the larger the martensite content the smaller the initial volume fraction of active ferrite which yields a higher initial deformation hardening rate. This explains the high energy absorbing capacity of DP steels with high volume fractions of martensite. Further, the effect of ferrite grain size strengthening in DP steels is important. The flow stress grain size sensitivity for DP steels is observed to be 7 times larger than that for single phase ferrite.
\end{abstract}

\section{Background}

The usage of advanced high strength steels, AHSS, has made it possible for the automotive industry to reduce weight and improve safety of vehicles. AHSS include steel types such as dual phase (DP), complex phase (CP), transformation induced plasticity (TRIP), and martensitic steels, of which DP steels are the most frequently used [1].

The properties of DP steels are characterized by a low yield strength due to the absence of Lüders bands and a high rate of deformation hardening, which results in a high tensile strength and good formability. DP steels also show a high energy absorbing ability which implies a good crashworthiness [2-5]. The explanation to the materials behavior is to be found in the microstructure, which in DP steels mainly consists of two phases: ferrite and martensite.

A number of attempts, for example, [6-10], have been made to physically describe the stress-strain behavior of DP steels. In most cases empirical relationships have been used but some physical models have been developed. One frequently used concept is the Ashby-model [11], which is based on the assumption that the dislocations can be placed in two categories: statistically stored dislocations (SSDs) and geometrically necessary dislocations (GNDs) with pile ups of dislocations in arrays. Unfortunately, these arrays have never been observed in high stacking fault energy crystals like ferrite. This has also been pointed out by Mughrabi [12] who further states that, "The increasing number of SGP (strain gradient plasticity) theories confirms that the search for a really satisfactory theory is still going on. Better microstructurally founded physical models should be pursued with priority before further development of rather formal, generalized concepts in which the physics tends to be hidden" [13].

Characteristic for a DP-steel is the very high initial deformation hardening rate, which decreases with strain and after a few percent of strain reaches a modest level. Using, for example, a Jaoul-Crussad plot, it can be shown that the deformation hardening behavior changes its characteristics with increasing strain. Korzekwa et ak. [14] proposed that the 
plastic deformation process may be divided into three strain intervals: Stage I: $0 \%-0.3 \%$, Stage II: $0.3 \%-3 \%$, and Stage III: $3 \%$ - strain to necking. This indicates that the deformation hardening of DP steels is more complicated than that of single phase materials.

It is well established that the flow stress of a crystalline material is proportional to the square root of the total dislocation density [15]. This implies that the deformation hardening behavior of DP steels is controlled by mechanisms that control dislocation generation and recovery. Further, it is also important to question whether the deformation process is homogeneous or inhomogeneous. To establish that, different techniques can be used to investigate the dislocation density development in the microstructure, that is, by applying TEM it is possible to detect variations in dislocation density in the ferrite grains as well as variations in the dislocation cell diameters. Further, it is possible to study how the dislocation density varies in areas close to the martensite-ferrite interface when compared with areas inside the ferrite grains. Using TEM it is also possible to decide whether the martensite deforms plastically or not.

Only a few TEM-investigations dealing with the characteristics of deformation hardening of dual phase steels are to be found in the literature. Korzekwa et al. [14] published interesting results from a TEM-investigation of a DP-steel containing about 10\% martensite. The steel was deformed to different strain levels and the microstructure was studied extensively. A summary is presented in Table 1.

The results from Korzekwa et al. imply that there are strain gradients in the ferrite in DP steels and that the plastic deformation process starts earlier and is faster in the areas close to the martensite phase than further away from the martensite-ferrite phase interface. A reasonable interpretation is that the natural stress concentrations that arise between the soft ferrite and the hard martensite yield an inhomogeneous deformation process.

Liedl et al. [16] used 3D FEM and TEM analysis to study the plastic deformation process in DP steels with varying amounts of martensite. Just as Korzekwa et al., they concluded that the dislocation density close to the interface of the martensite particles was higher than the density in the interior of the ferrite grains. This is supported by the TEM-investigations by Rigsbee et al. [17] who also detected dislocation density gradients within the ferrite. Further, Liedl et al. pointed to the possibility that the phase transformation from austenite to martensite, which follows intercritical annealing, gives rise to a skeleton-shaped network of deformation hardened ferrite, a network that partly links the martensitic islands together and partly governs the initial deformation process.

In a recently published paper [18] the Bergström dislocation model for the stress-strain deformation process in single phase materials was used to study the mechanical behavior of a DP-steel containing about $35 \mathrm{vol} \%$ martensite. The model is based on a "homogeneous" dislocation density, $\rho$, and the assumption that the deformation process is controlled by generation, immobilization, and remobilization of dislocations. Despite no adjustments being made for the special properties of DP-steel, the model accurately represented the stress-strain behavior of the investigated DP-grade. An important parameter in the model is the dislocation mean free path, $s$. In single phase materials the dislocation mean free path normally decreases with strain. In the investigated DP-steel it was necessary to accept that the dislocation mean free path increased with strain from an initial value of $\sim 0.03 \mu \mathrm{m}$ to a final value of $\sim 0.3 \mu \mathrm{m}$, that is, a tenfold increase. Since it is reasonable to assume that the dislocation mean free path should decrease with increasing strain and increasing dislocation density, the result indicates the presence of some type of inhomogeneous deformation process resulting in this unrealistic result. In [18] it was observed that the value of the dislocation remobilization parameter, $\Omega$, increased to values well above 5 with increasing amounts of martensite. This seems unrealistic since the plastic deformation is supposed to be located in the ferrite where $\Omega$ normally takes the value of 5 at room temperature [19].

The aim of this study is to find a physical description of the deformation behavior of DP steels. In the present paper it will be clear that the peculiar results in [18] emanate from the differences in the measured macroscopic strains and the actual strains in the ferrite phase. A new theory for the plastic deformation process of DP steels is therefore presented. In the study we have proceeded from the fundamentals of the original Bergström dislocation theory [19] and further developed and adjusted it to DP steels, that is, taking the inhomogeneous deformation process into account. The result is a theory that not only explains the overall large deformation hardening in a simple way, but also explains the initial very high work hardening behavior. The impact of martensite content and ferrite grain size on the deformation behavior is also addressed. Since the model is physically based, it is possible to analyze and discuss in detail the effect of different material parameters on the mechanical properties of DP steels.

\section{Theory}

The theory is discussed in the light of results from experimental uniaxial tensile testing, light optical and SEM/EBSDstudies of the microstructure. Since the new theory is developed from the original Bergström dislocation theory, it is appropriate to start with a short résumé.

2.1. The Original Bergström Theory: A Résumé. It is well established [15] that the true flow stress, $\sigma(\varepsilon)$, in crystalline materials and alloys is related to the total dislocation density $\rho(\varepsilon)$ as

$$
\sigma(\varepsilon)=\sigma_{i 0}+\sigma_{\text {def }}(\varepsilon)=\sigma_{i 0}+\alpha \cdot G \cdot b \sqrt{\rho(\varepsilon)}
$$

also known as the Taylor equation, where $\sigma_{i 0}$ is the friction stress, $\sigma_{\text {def }}$ is the work hardening component of the flow stress, $\alpha$ is a dislocation strengthening constant, $G$ is the shear modulus, $b$ is the nominal value of the Burgers vector, and $\varepsilon$ is the true strain. If the validity of (1) is accepted the main problem in formulating a dislocation theory for the true stress-true strain behavior of metals and alloys is to derive a relationship for $\rho(\varepsilon)$. 
TABLE 1: Summary of dislocation substructure development in a C-Mn-Si dual-phase steel in tension [14].

\begin{tabular}{|c|c|c|}
\hline True plastic strain (\%) & Typical ferrite dislocation substructures & $\begin{array}{l}\text { Variation of the substructure within a typical } \\
\text { ferrite grain }\end{array}$ \\
\hline 0 & Very low average dislocation density & High dislocation density adjacent to martensite \\
\hline 1 & No cells: a few straight, planar dislocation walls & Dislocation density higher near martensite \\
\hline 2 & Incipient cells: many long, straight walls & Cell structure generally forms first near martensite \\
\hline 7 & Well-developed cell structure; thick cell walls & $\begin{array}{l}\text { Cell size smaller near martensite }(\sim 0.4 \mu \mathrm{m}) \text { than } \\
\text { away from martensite }(\sim 0.7 \mu \mathrm{m})\end{array}$ \\
\hline 14 & $\begin{array}{l}\text { Well-developed cell structure with many straight, } \\
\text { thin cell walls }\end{array}$ & Cell sizes approximately the same as for $7 \mathrm{pct}$ strain \\
\hline
\end{tabular}

For single-phase metals and alloys Bergström [19] derived the following expression for the variation of the total dislocation density with strain:

$$
\frac{d \rho(\varepsilon)}{d \varepsilon}=\frac{\bar{m}}{b \cdot s(\varepsilon)}-\Omega \cdot \rho(\varepsilon)
$$

where $\rho$ is the total dislocation density, $s(\varepsilon)$ is the mean free path of dislocation motion, $b$ is the nominal value of Burger's vector, $\Omega$ is a strain-independent material constant representing the remobilization (dynamic recovery) of immobile dislocations, and $\bar{m}$ is the Taylor constant.

The following relationship for $s(\varepsilon)$ has proved [19] to give an excellent description of the strain dependence of the dislocation mean free path, $s$, in single phase metals

$$
s(\varepsilon)=s_{0}+\left(s_{1}-s_{0}\right) \cdot e^{-k \varepsilon},
$$

where $s_{1}$ and $s_{0}$ are the initial and final values of $s . k$ is a rate constant determining the rate at which $s(\varepsilon)$ goes from $s_{1}$ to $s_{0}$.

\subsection{A Dislocation-Based Theory for the Uniaxial Stress-} Strain Behavior of DP-Steel. In order to adjust the original Bergström dislocation model to DP-steel, an important question to consider is whether or not the martensite in DP steels deforms plastically. It has been observed [20] that this primarily depends on the hardness of the martensite, that is, its carbon content. If the carbon content of the martensite is low there are indications that the martensite may start to deform plastically, whereas martensite with high carbon contents remains elastic at least up to strains to necking [16]. In modern DP steels the carbon content of the martensite is usually comparatively high (see Section 3.1). In the present study we therefore assume that the martensite does not deform plastically and consequently the plastic deformation process is localized to the soft ferrite phase.

Further, it is assumed that the plastic deformation process in the ferrite is inhomogeneous. According to previous studies $[14,18]$ the deformation process seems to be initiated close to the martensite particles, which are located in the ferrite grain boundaries. The deformation process also seems to be faster close to the martensite particles compared with deformation process in the ferrite further away from the martensite-ferrite interface. This implies that the initial volume fraction of active ferrite is small which results in a high rate of dislocation creation, faster and earlier development of a cell substructure, and smaller cell diameters. However, with increasing strain the deformation process propagates towards the centers of the ferrite grains which yields an increase in the active volume fraction of ferrite and hence to a retardation of the rate of dislocation creation.

There are several reasons for the occurrence of this type of procedure around the martensite particles. One reason is that the austenite to martensite transformation generates large tensile residual stresses in the phase interface, which during tensile testing will easily be released and generate plastic deformation. Another reason can be ascribed to the compatibility condition; during tensile testing large stresses will arise in the martensite-ferrite interface since the martensite remains elastic. These stresses may however be eliminated through the generation of cascades of dislocations in the nearest surroundings of the martensite particles. Via the motion of these dislocations the highly stressed areas will be released. It is most likely that these two phenomena act in parallel, resulting in a large initial deformation hardening which starts in the vicinity to the martensite particles.

2.3. Basic Assumptions. The dislocation theory is developed for DP steels and it is based on the following assumptions.

(1) The theory is valid for uniaxial strain and for tensions up to necking.

(2) The work hardening process starts in the ferrite close to the phase interface of ferrite and martensite, partly as a result of the presence of high residual stresses caused by the transformation from austenite to martensite, partly due to the incompatibility conditions which give rise to stress concentrations in these areas. The work hardening process is thus initially located in the ferrite close to the martensite surfaces. As a result of increasing work hardening in these areas, the deformation process is forced to proceed inwards the ferrite grains due to lower hardening resistance there.

(3) The investigated DP steels consist of the following volume fractions:

(i) martensite, $f_{m}$, which deforms elastically but not plastically,

(ii) active ferrite, $f$, which deforms elastically and plastically 
(iii) non-active ferrite, $f_{\text {undef, }}$ which deforms elastically and successively deforms plastically.

(4) A non-homogeneity factor $f$ is introduced which is defined as the active part of the total volume fraction of ferrite, $f_{0}$, participating in the plastic deformation process. At small strains, that is, in the beginning of the deformation process, $f \ll f_{0}$. With increasing strain, $f$ is assumed to grow towards $f_{0}$. As a result of the continuously increasing volume fraction of active ferrite, the rate of dislocation creation and work hardening decreases with increasing strain.

(5) The undeformed fraction of ferrite, that is, the continuously decreasing amount $f_{0}-f$, may be considered as hard, not participating in the deformation process and can in that respect be compared with the martensite fraction. Therefore, stress concentrations may arise in between the deformed and undeformed ferrite as well. This reminds of the Lüder-phenomenon where a front separates deformed ferrite from undeformed.

(6) The plastic deformation process does not necessarily start in all ferrite grains at the same time but may randomly and continuously be initiated at different locations during the plastic deformation process.

(7) Although the dislocation density will show local variations due to the inhomogeneous plastic deformation, (1), is assumed to hold for the average dislocation density in the active ferrite volume.

(8) The mean free path of mobile dislocations is assumed to decrease exponentially with strain in accordance with (3).

2.3.1. The Active Volume Fraction Ferrite. When loading a tensile test specimen of a DP-steel we will assume that the load is distributed on the entire volume of the sample, that is, on the martensite, $f_{m}$, on the active ferrite, $f$, and the undeformed ferrite, $f_{\text {undef. }}$.

If the stress acting on the regions of active ferrite is $\sigma_{f}$, the same stress is also acting on the other two fractions but only in an elastic way. The global stress, $\sigma$, on the test specimen may therefore be written

$$
\sigma=\left(f_{m}+f(\varepsilon)+f_{\text {undef }}\right) \cdot \sigma_{f},
$$

where $f_{m}+f(\varepsilon)+f_{\text {undef }}=1$. This implies that the global stress, $\sigma$, is equal to the local stress, $\sigma_{f}$, acting on the active volume fraction of ferrite. The plastic strain dependence of the dislocation density, $\rho$, in the active ferrite may according to the chain-rule be written

$$
\frac{d \rho}{d \varepsilon_{f}}=\frac{d \rho}{d \varepsilon} \cdot \frac{d \varepsilon}{d \varepsilon_{f}},
$$

where $\varepsilon_{f}$ is the local strain in the active ferrite and $\varepsilon$ is the global strain. Since the global strain $\varepsilon$ is related to the local strain, $\varepsilon_{f}$, as

$$
d \varepsilon \cong f \cdot d \varepsilon_{f}
$$

the global strain dependence of the total dislocation density for a DP-steel may be expressed as (compare with (2))

$$
\frac{d \rho(\varepsilon)}{d \varepsilon}=\frac{1}{f} \cdot\left[\frac{\bar{m}}{b \cdot s(\varepsilon)}-\Omega \cdot \rho(\varepsilon)\right] .
$$

Furthermore we assume that the strain dependence of the volume fraction $f$ may be written as

$$
\frac{d f(\varepsilon)}{d \varepsilon}=r\left(f_{0}-f(\varepsilon)\right),
$$

where $r$ is a material parameter that controls the rate of this progress. Integrating (8) the following relationship is achieved

$$
f(\varepsilon)=f_{0}+\left(f_{1}-f_{0}\right) \cdot e^{-r \cdot \varepsilon},
$$

where $f_{1}$ is the initial active volume fraction of ferrite taking part in the deformation process and $f_{0}$ is the total amount of ferrite. $f(\varepsilon)$ thus starts from the value of $f_{1}$ and hereafter grows with increasing strain towards $f_{0}$.

As mentioned, $\varepsilon$ is the global plastic strain. A low fraction of active ferrite, $f(\varepsilon)$, will thus give rise to a high increase in dislocation density and lead to an observed high initial rate of work hardening which decreases with increasing strain as $f(\varepsilon)$ increases. Using (3) and (9) in (7) we finally achieve an expression for the inhomogeneous deformation behavior of ferrite in DP-steel;

$$
\frac{d \rho}{d \varepsilon}=\frac{1}{f_{0}+\left(f_{1}-f_{0}\right) \cdot e^{-r \cdot \varepsilon}} \cdot\left[\frac{\bar{m}}{b \cdot\left(s_{0}+\left(s_{1}-s_{0}\right) \cdot e^{-k \cdot \varepsilon}\right)}-\Omega \cdot \rho\right] .
$$

Equation (10) gives us the dislocation strain dependence for a DP-steel expressed in the ferrite phase parameters, that is, a description of the continuous localization process in the DP-steel. A comparison between (10) and (2), which is the original Bergström expression for the "homogeneous" $\rho$ - $\varepsilon$ behavior in pure ferrite, shows that (10) transcends into (2) if $f_{0}=f_{1}=1$, that is, if we assume that $f_{m}=0$ and that the deformation is "homogeneous".

Based on the reasoning above we now have the possibility to, in a mathematical and physical way, approximate how the plastic deformation in a DP-steel proceeds up to necking. In practice this means that the plastic deformation process is inhomogeneous with local strain gradients in the ferrite as a consequence. We can therefore expect to experimentally observe large variations in plastic deformation in the ferrite grains as well as differences between ferrite grains. Since the model is physically based, it is also possible to analyze and discuss in detail the effect of different material parameters on the deformation behavior of DP steels.

\section{Experimental}

3.1. Materials Selection. The study includes four commercial high strength steel grades with varying martensite content. The steels are continuously cast to slabs, reheated in the slab reheating furnace, and hot rolled according to normal production routines at SSAB. Nominal chemical composition of the grades is presented in Table 2. 
TABle 2: Nominal chemical composition (wt \%), Fe bal.

\begin{tabular}{lcccc}
\hline Grade & $\mathrm{C}$ & $\mathrm{Mn}$ & $\mathrm{Si}$ & $\mathrm{Nb}$ \\
\hline DP500 & 0.08 & 0.65 & 0.3 & - \\
DP600 & 0.11 & 0.90 & 0.4 & - \\
DP800 & 0.13 & 1.50 & 0.2 & 0.015 \\
DP980 & 0.15 & 1.50 & 0.5 & 0.016 \\
\hline
\end{tabular}

To achieve the final DP properties the steels are subsequently cold rolled and annealed in a continuous annealing line using process parameters according to Table 3. Samples for tensile testing were taken from the outlet of the continuous annealing line, two specimens of each grade were used, that is, the double samples have the same nominal chemical composition but do not necessarily originate from the same strip or from the same position on the strip. (Some samples originate from the head of the strip, some are mid-section samples and some are taken from the tail of the strip.) This can explain the internal variation in tensile behavior. The martensite fraction is measured using a grid and a point counting method, evaluating 5 image fields for each sample, that is, 10 image fields for each grade. The scattering in martensite fraction is about $\pm 2 \%$ for each grade.

3.2. Tensile Testing and Microstructure. Tensile testing was performed at room temperature, $90^{\circ}$ to the rolling direction, using the equipment Galdabini Sun20, EN 10002 standard machine. A constant strain rate of $2.5 \cdot 10^{-3} \mathrm{~s}^{-1}$ was applied to all samples, double specimens were used for all grades.

Scanning electron microscopy has been used to thoroughly investigate the microstructure of the DP steels. Attention has been paid to shape, distribution and size of the martensitic phase. EBSD was applied to study misorientation gradients in the ferrite, in deformed as well as in undeformed DP800, in order to detect strain gradients.

\section{Results}

As stated above, the aim of this work is to find a physical description of the deformation behavior of DP steels. We will therefore discuss the connection between microstructure and plastic behavior and in detail analyze and discuss the physical interpretation of the parameters included in the theory.

\subsection{Microstructure of Undeformed and Deformed Materials.} Essential in this study is the connection between plastic deformation behavior and microstructure. Therefore, samples were taken from the undeformed head of the tensile test specimens, hot mounted, ground, polished, and etched with Nital. The cross-section, portrayed in Figure 1, with the rolling direction (RD) horizontally and the normal direction (ND) vertically, was thoroughly examined using scanning electron microscopy (SEM), InLens detector. Settings were $\mathrm{ETH}=5.0 \mathrm{kV}, \mathrm{WD}=3 \mathrm{~mm}$, and standard aperture $30 \mu \mathrm{m}$. In Figure 1, the martensite grains appear as light areas and the ferrite grains as dark gray areas.
Comparing the microstructure of DP500 and DP600 with DP800 and DP980, there is a large difference in grain size, both regarding ferrite grain size and martensite grain size, which is attributed to the addition of $\mathrm{Nb}$ to DP800 and DP980, since $\mathrm{Nb}$ is a well-known grain size reducing agent. The presence of particles appearing as white spots in the ferrite of DP500 and DP600 is also visible at this magnification. These are most likely iron carbides nucleated when quenching from the intercritical annealing temperature followed by growth when tempering. These carbides are not as pronounced in DP800: which can be explained by the smaller grain size and the larger amount of martensite of DP800; the smaller the grain size and the larger the austenite fraction, the shorter the diffusion distances prior to quenching facilitates a redistribution of carbon. However, DP800 as well as DP980 contains Nb and therefore also niobium carbonitrides, $\mathrm{Nb}(\mathrm{C}, \mathrm{N})$, to some extent. These $\mathrm{Nb}(\mathrm{C}, \mathrm{N})$ are however not visible using SEM at the chosen magnification.

The carbon content of the martensite was calculated using a simple rule of mixture, assuming that the volume consists solely of martensite and ferrite with a carbon content of $0.025 \mathrm{wt} \%$. This is of course a simplification, but is regarded as a fairly good approximation. The variation in carbon content of the martensite is also supported by the appearance of the martensite: the lower the carbon content of the martensite the coarser the martensite structure. As seen in Figure 1, the martensite in DP500 and DP600, which in both cases has a carbon content of approximately $0.6 \%$, appears to be plainer compared to the martensite in DP980 with a carbon content of about $0.3 \%$. DP980 is temper annealed at $210^{\circ} \mathrm{C}$ in contrast to the temper annealing temperature of $300^{\circ} \mathrm{C}$ for the other grades. The temper annealing temperature will also affect the appearance of the martensite; the higher the temperature, the coarser the appearance of the martensite due to precipitation of carbides.

4.2. EBSD Studies of Deformed Samples. Electron backscatter diffraction (EBSD) technique has been used to study strain gradients in terms of misorientations, both regarding undeformed DP800 as well as DP800 strained to approximately $8 \%$ total strain. The result from an EBSD analysis of the undeformed material is presented in Figure 2.

The coloring shows the crystallographic misorientation relative to a reference point at the centre of a grain. The crystal rotations, that is, local misorientations, are assumed to be caused by strain gradients. Blue color represents small misorientations that is, small strain gradients and red represents large misorientation, that is, larger strain gradients. Figure 2 shows that the misorientations are smaller in the centre of the grains and increase as we approach the ferritemartensite phase interface.

In Figure 3, where the material is strained to $8 \%$, we see that the blue areas (small misorientations) have diminished, whereas the green, yellow, and red areas close to the martensite phase have increased, that is, the material experience gradually larger misorientations. As we know that the dislocation density increases with strain we interpret 
TABLE 3: Annealing conditions: soaking section $\left({ }^{\circ} \mathrm{C}\right)$, tempering section $\left({ }^{\circ} \mathrm{C}\right)$, temper rolling (\% total strain), martensite fraction, martensite carbon content $(\mathrm{wt} \%)$, and ferrite grain size $[\mu \mathrm{m}]$.

\begin{tabular}{llllllc}
\hline Grade & $T$ (soaking) & $T$ (temp.) & Temper rolling & Martensite fraction & $\begin{array}{l}\text { Estimated martensite } \\
\text { carbon content }\end{array}$ \\
\hline DP500 & 760 & 300 & 0.6 & 0.13 & 0.60 & 10.8 \\
DP600 & 760 & 300 & 0.6 & 0.18 & 0.60 & 8.4 \\
DP800 & 760 & 300 & $<0.2$ & 0.25 & 0.51 & 0.31 \\
DP980 & 780 & 210 & $<0.2$ & 0.48 & 3.7 \\
\hline
\end{tabular}

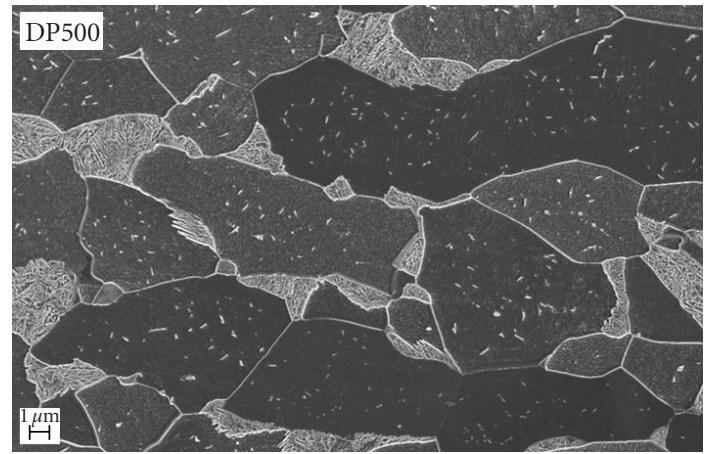

(a)

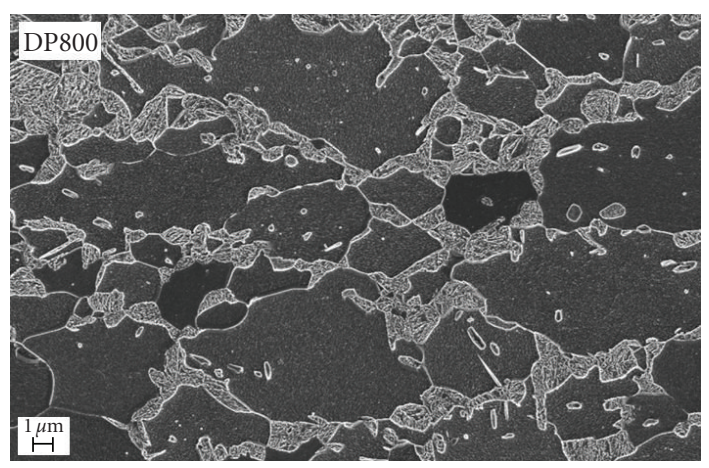

(c)

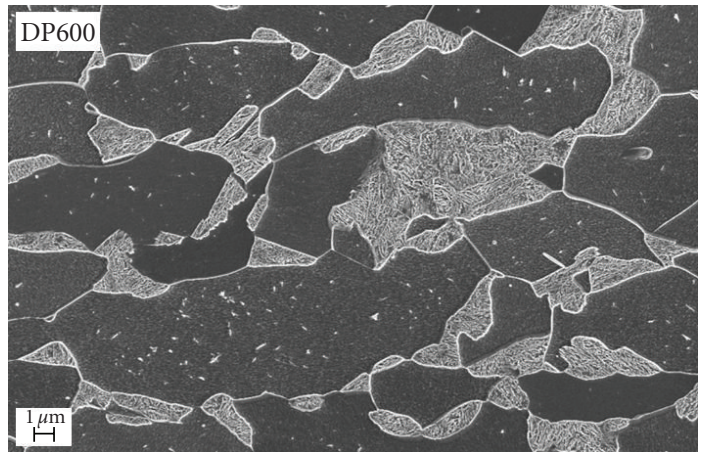

(b)

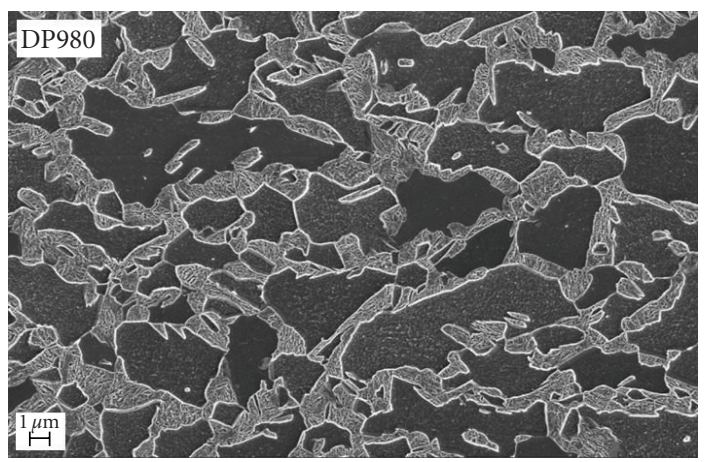

(d)

FIGURE 1: SEM-pictures of the investigated grades. The martensite grains appear as light areas and the ferrite grains as dark gray areas.

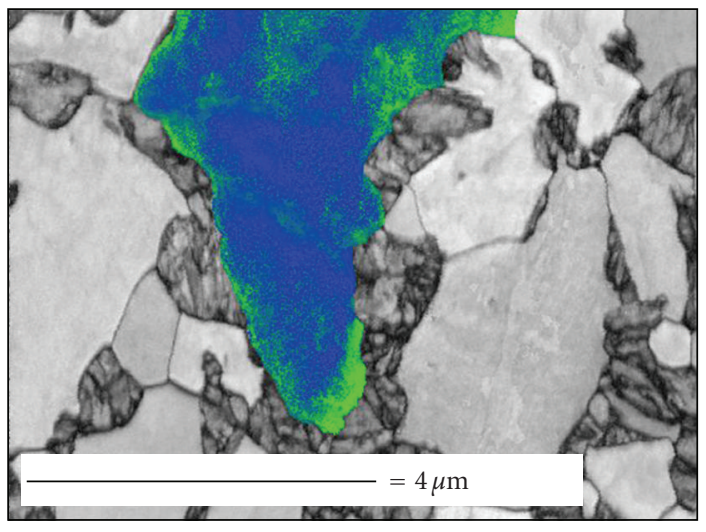

(a)

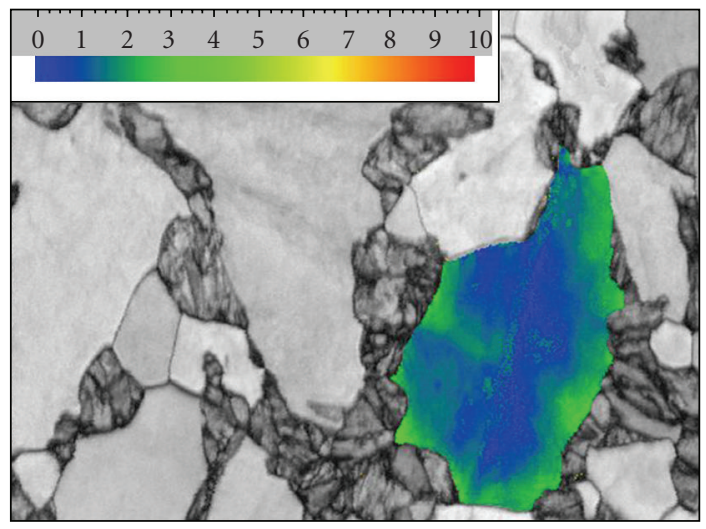

(b)

FIGURE 2: EBSD analyses of undeformed (as-produced) DP800. The coloring indicates misorientation angle in degrees relative to the reference point (in this case colored blue). Small misorientations are visible in the ferrite close to the martensite-ferrite phase interphase. 


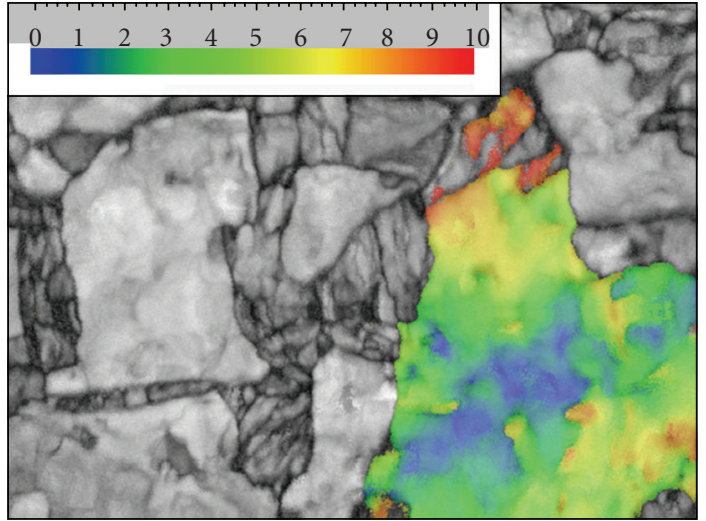

(a)

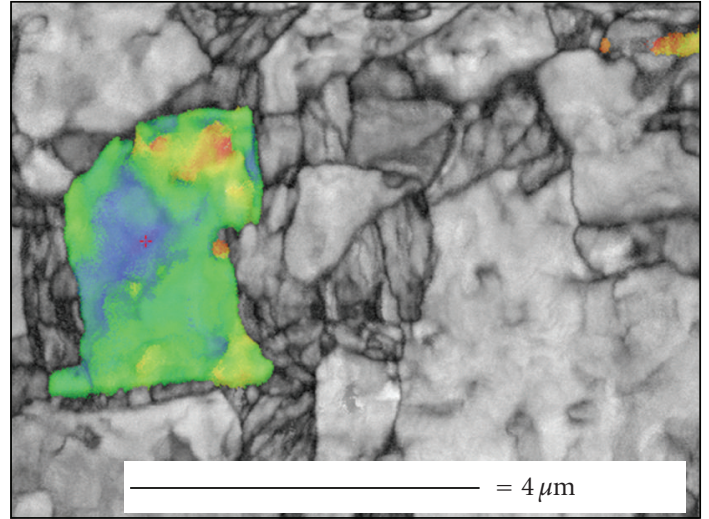

(b)

FiguRE 3: EBSD analyses of deformed DP800 strained to 8\%. The coloring indicates misorientation angle in degrees relative to the reference point (in this case colored blue). The red, yellow, and green coloring - the more misoriented ferrite-increases with strain. It is observed that the ferrite with the highest level of misorientation is located close to the martensite-ferrite interface.

this change in misorientation as an increase in dislocation density. These observations are in good agreement with the ones made by Korsekwa et al. [14].

From Figure 3 we see that the plastic deformation process in this DP-steel varies substantially inside the ferrite grains. It cannot be excluded that some areas in the inner parts of a grain may not take part in the plastic deformation at all or to a very small extent. However, it should be emphasized that what we see in Figure 2 and Figure 3 is the local misorientation deviation from a reference point manually set in the centre of the grain. Different relative misorientations will be observed depending on where the reference point is set. Additional measurements, not presented here, show that the deviation in misorientation in the ferrite is larger close to the border of the martensite, irrespective of where the reference point is set.

4.3. Tensile Testing. A summary of the tensile properties is presented in Table 4 and the true stress-strain curves are shown in Figure 4. It is worth to notice that for DP500, DP600, and DP800, the difference between the double samples is small, whereas for DP980 the discrepancy is quite large. The difference, is however, within the normal range of variation for production materials at this strength level.

Studying the flow curves it is also clear that there is a large variation between the steel grades regarding the initial deformation stage. It is clear that the deformation hardening rate increases when the martensite content increases.

The relationship between yield strength and martensite volume fraction as well as tensile strength and martensite volume fraction is observed to be linear, see Figure 5, where the mean values of the double samples (values from Table 4) are presented. A linear relationship was also found by AR Marder [21], who studied DP steels with martensite content up to $65 \%$. From Figure 4 it is obvious that the strain to necking decreases with increasing martensite content. This is further commented on in Section 4.6.4.
TABle 4: Tensile properties, achieved from tensile testing using constant strain rate $2.5 \cdot 10^{-3} \mathrm{~s}^{-1}$.

\begin{tabular}{llllll}
\hline Grade & Th [mm] & YS [MPa] & TS [MPa] & UE (\%) & A80 [\%] \\
\hline DP500 (B3) & 1.47 & 352 & 550 & 15 & 25 \\
DP500 (B4) & 1.45 & 366 & 548 & 15 & 26 \\
DP600 (C3) & 1.48 & 404 & 643 & 13 & 21 \\
DP600 (C4) & 1.51 & 404 & 635 & 12 & 21 \\
DP800 (D3) & 1.55 & 540 & 822 & 10 & 15 \\
DP800 (D4) & 1.49 & 534 & 804 & 10 & 16 \\
DP980 (E3) & 1.36 & 733 & 1117 & 8 & 10 \\
DP980 (E4) & 1.35 & 620 & 1013 & 8 & 14 \\
\hline
\end{tabular}

4.4. Prerequisites for the Fitting Procedure. A special Matlab subroutine, based on the Matlab Curve Fitting Toolbox, was designed for the purpose of this study and (1) and (10) were fitted to experimental true stress-strain data. In the fitting procedure the following parameters were kept constant: $G=80000 \mathrm{MPa}, b=2.5 \cdot 10^{-10} \mathrm{~m}, \bar{m}=2, \alpha=0.5$, $\Omega=5, \rho_{0}=1.5 \cdot 10^{14} \mathrm{~m}^{-2}$ and $f_{0}=1-f_{m}$. The remaining parameters were allowed to vary freely within reasonable physical limits.

Previous studies [19] have shown that $\Omega$ in ferrite attains the value of approximately 5 at room temperature. The value chosen for the grown-in dislocation density, $\rho_{0}$, is somewhat higher than that for an annealed material and the increase in the value compensates for the skin-pass rolling effect for the temper rolled grades. The phase transformation from austenite to martensite conduces to a higher dislocation density in the vicinity to the martensite particles as well as in the martensite phase itself. The higher martensite content diminishes the effect of temper rolling but increases the effect of phase transformation on the dislocation density. Setting $\rho_{0}$ to a constant value for all grades therefore seems like a reasonable approximation. 

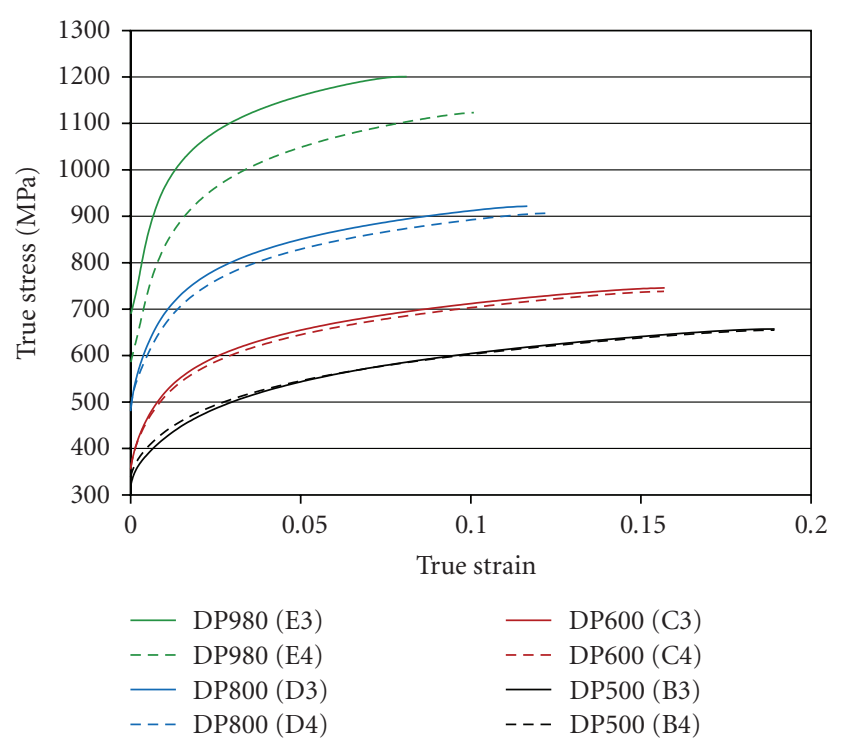

Figure 4: Experimental true stress-true strain curves for the investigated DP steels, for strains up to necking.

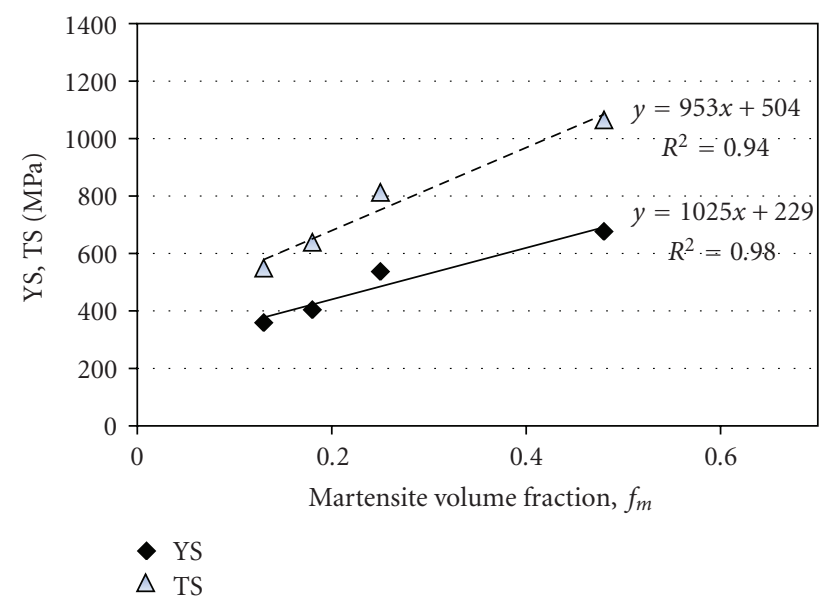

FIGURE 5: Yield strength (YS) and tensile strength (TS) versus martensite volume fraction. Mean values of YS and TS presented in Table 4.

4.5. Output from the Fitting Procedure. There are several outputs resulting from the fitting procedure and one example is shown in Figure 6. Figure 6(a) shows the calculated stressstrain curve for DP500 (sample B3) and the cross at the end of the stress-strain curve indicates the calculated stress and strain values at necking. In Figure 6(c) the discrepancy between calculated and experimental values is plotted (as dots) and the mean error over the strain interval is $e=0.072$ $\mathrm{MPa}$, that is, a very good fit. The graph in the middle, Figure 6(b), shows the calculated dislocation density as a function of strain. The slope of the curve tells us that the initial rate of dislocation generation is very high and then diminishes with increasing strain. The initial dislocation density, $\rho_{0}$, is assumed to be $1.5 \cdot 10^{14} \mathrm{~m}^{-2}$, while the dislocation density at necking is $1.7 \cdot 10^{15} \mathrm{~m}^{-2}$, that is, more than a tenfold increase.
The fit between the model and the experimental stressstrain data is very good for all steel grades. Another example is presented in Figure 7, which shows the calculated stressstrain curve for DP800 (sample D3) as well as the fitting mean error. The mean error over the strain interval is $0.069 \mathrm{MPa}$, that is, also a very accurate fit.

Other outputs from the fitting procedure software are the strain dependence of the deforming volume fraction of ferrite, $f(\varepsilon)$ as well as the dislocation mean free path $s(\varepsilon)$. In Figure $8, f(\varepsilon)$ for DP500 is plotted and it is interesting to note that, at the start of the tensile test, only $24 \%$ of the ferrite is calculated to participate in the deformation process, that is, $f_{1}=0.239$. When straining continues, $f(\varepsilon)$ increases and slowly approaches the upper limit $f_{0}$. The rate of this process is determined by the rate constant, $r$, see (9), and it is evident from Table 5 that $r$ is almost independent of steel grade and approximately equal to 25 under the present experimental conditions.

In the deforming ferrite volume the mean free path of dislocation motion, $s(\varepsilon)$, is quickly diminishing from a start value of $s_{1}=8.7 \cdot 10^{-7} \mathrm{~m}$ to a final value of $s_{0}=5.94 \cdot 10^{-7} \mathrm{~m}$ (in the case of DP500), see Figure 9. This transition is controlled by the parameter $k$, compare (3). The rapid decrease in $s$ is related to the relatively high $k$-values, larger than, $100-$ for the investigated grades, see Table 5 .

The values obtained for $s_{1}$ and $s_{0}$, lying in the interval $1.0-0.25 \mu \mathrm{m}$, are in well accordance with the results obtained in previous studies on ferrite in DP-steel, see, for example, Korzekwa et al. [14]. The values of $s_{1}$ and $s_{0}$ are also reasonable according to that which is observed in the microstructure. Iron carbides are visible in the ferrite in DP500 and DP600 at the used magnification and the average distance between these particles is estimated to approximately $0.5-1 \mu \mathrm{m}$. This would be the restriction of the dislocation cell diameters, that is, the magnitude of $s_{0}$. DP800 and DP980 do most likely contain $\mathrm{Nb}(\mathrm{C}, \mathrm{N})$, small densely distributed particles, not visible in Figure 1, but affecting the dislocation mean free path, see also Figure 12.

In the example above, $s$ reaches its final value $s_{0}$ after approximately 3\%-4\% plastic strain. This indicates that, in the deforming active volume, a final dislocation network controlling dislocation motion is quickly developed. At larger strains $s$ is strain independent and equal to $s_{0}$.

4.6. Connection between Experimental and Theoretical Parameters. Developing a physically based theory a minimum number of physically based parameters is needed. In the present model all parameters have a well-defined physical meaning, which implies that we can make comparisons with experimental observations; , for example, compare $s_{0}$ with dislocation cell diameters, the friction stress with the flow stress at $\varepsilon=0$, the initial fraction of active ferrite, $f_{1}$, with the initial rate of deformation hardening, and so forth. Repeating the fitting with reasonable start-values we observe that the values of the final parameters converge towards the same result.

When developing the theory by accounting for the inhomogeneous deformation, it was necessary to introduce 


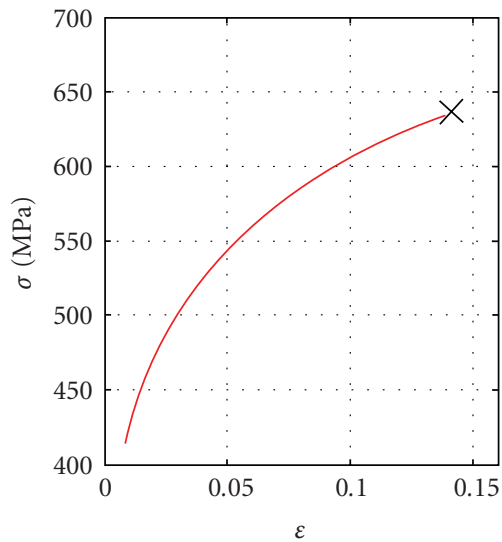

(a)

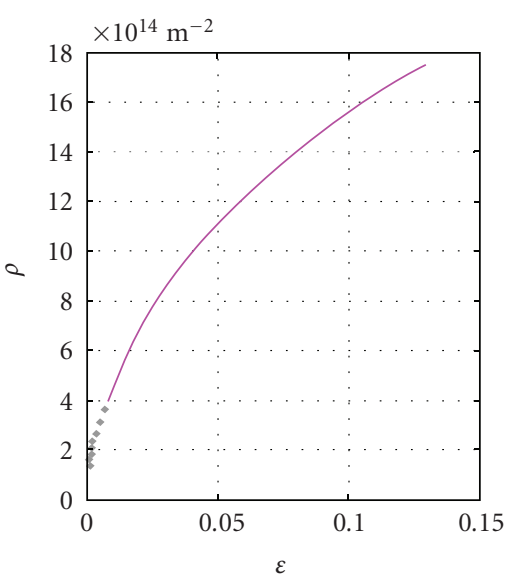

(b)

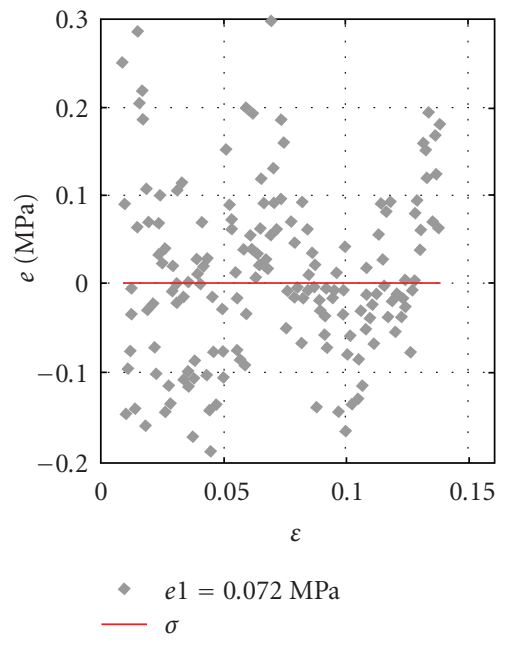

(c)

Figure 6: Calculated stress-strain curve for DP500 (sample B3) (a), calculated dislocation density versus true strain (b), and mean discrepancy between model and experimental stress-strain values (c).

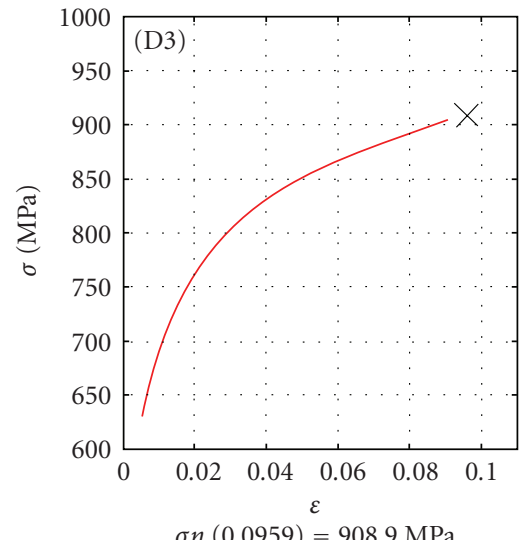

(a)

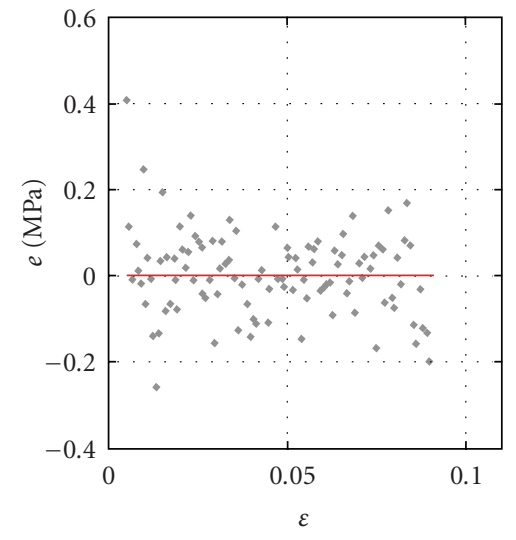

- $e 1=0.069 \mathrm{MPa}$

(b)

Figure 7: Calculated stress-strain curve for DP800 (D3) (a) and the discrepancy between the model and experimental values (b). Mean fault value over the strain interval is $0.069 \mathrm{MPa}$.

two additional physically based parameters: $f_{1}$ and $r$. The number of parameters involved in the present theory is therefore quite large, but all still physically indispensable. However, there might be some type of correlation between some of the parameters and further work will be required to investigate if that is the case. As an example, the rate constant $r$, see (9), seems to be approximately independent on martensite content and equal to about 25 , see Table 5 . If this is generally valid, the number of varying parameters may be cut down by one.

We will start by giving some general comments related to the results summarized in Table 5 . We will then discuss in more detail how the friction stress, $\sigma_{i 0}$, the work hardening component, $\sigma_{\text {def }}(\varepsilon)$, and the flow stresses, $\sigma(\varepsilon)$, (see $(1)$ ), are related to martensite volume fraction, $f_{m}$, ferrite grain diameter, $d$, and final mean free path of dislocation motion, $s_{0}$. We will also try to find out if there exist additional simple connections between theoretical and experimental parameters which may lead us to a better understanding of the plastic deformation process in DP steels. A summary of the parameter values from the fitting procedure for all grades is presented in Table 5 . The accuracy of fit $(e)$ is very good for all samples, less than $0.11 \mathrm{MPa}$ over the strain interval. As seen in Figure 5 and Table 4, the deviation between the double samples is small for all grades except for DP980, that is, the difference between the parameter values is negligible. The difference between the double samples of DP980 will of course be larger but will only marginally affect the interpretations of the correlations presented in Section 4.6. 
TABLE 5: Results from the fitting procedure, compilation of parameter values. $f_{m}=$ volume fraction of martensite, $f_{1}$ : initial active volume fraction of ferrite, $r$ : rate constant, $s_{1}=$ start value of dislocation mean free path, $s_{0}=$ final value of dislocation mean free path, $k$ : rate constant, $\sigma_{i 0}$ : friction stress, $\sigma_{n}$ : flow stress at necking, $\varepsilon_{n}$ : strain at necking, $e$ : mean error (discrepancy between model and experimental values). Mean values from double samples shown in Table 4.

\begin{tabular}{lcccccccccc}
\hline & $f_{m}$ & $f_{1}$ & $\mathrm{r}$ & $s_{1}(\mathrm{~m})$ & $s_{0}(\mathrm{~m})$ & $k$ & $\sigma_{i 0}[\mathrm{MPa}]$ & $\sigma_{n}[\mathrm{MPa}]$ & $\varepsilon_{n}$ & $\mathrm{e}[\mathrm{MPa}]$ \\
\hline DP500 & 0.13 & 0.244 & 27.5 & $8.2 E-07$ & $6.2 E-07$ & 102 & 219 & 632 & 0.138 & 0.076 \\
DP600 & 0.18 & 0.127 & 25.1 & $5.9 E-07$ & $4.5 E-07$ & 269 & 228 & 720 & 0.116 & 0.085 \\
DP800 & 0.25 & 0.083 & 23.1 & $5.5 E-07$ & $3.5 E-07$ & 226 & 331 & 900 & 0.097 & 0.068 \\
DP980 & 0.48 & 0.075 & 27.4 & $9.1 E-07$ & $2.6 E-07$ & 732 & 475 & 1162 & 0.086 & 0.105 \\
\hline
\end{tabular}

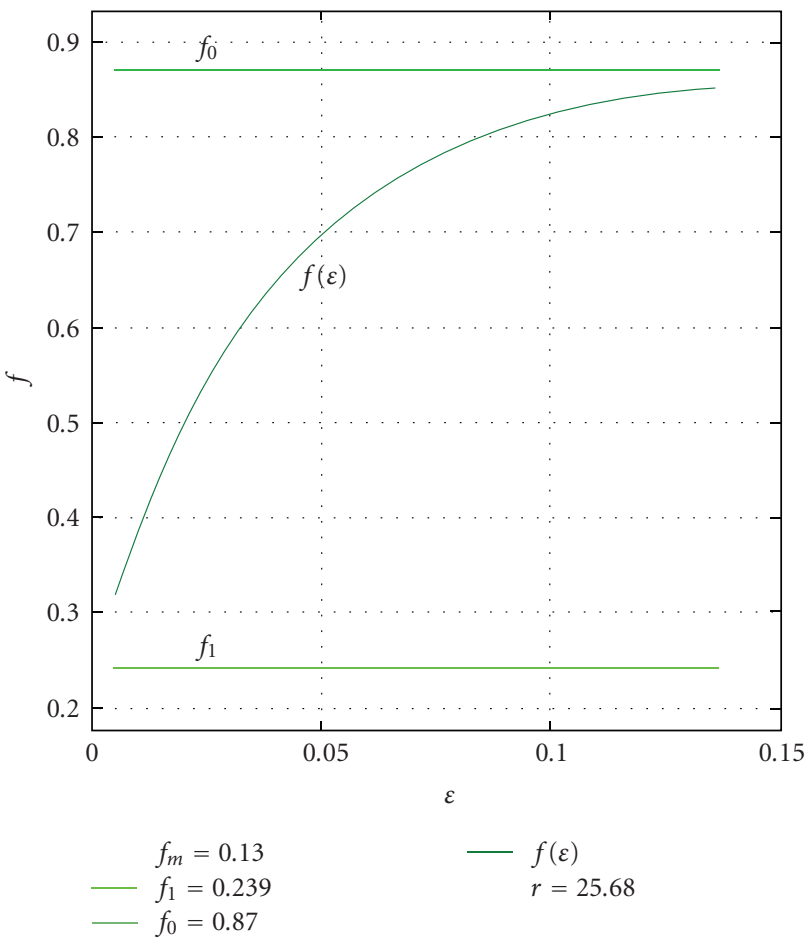

Figure 8: DP500 (B3): active volume fraction of ferrite $f(\varepsilon)$ taking part in the plastic deformation.

4.6.1. The Initial and Final Volume Fractions $f_{1}$ and $f_{0}$ and the Rate Constant $r$. In Figure 10, $f_{1}$ is plotted versus martensite content, $f_{m}$, and it is apparent that $f_{1}$ decreases with increasing $f_{m}$, see also Table 5 . This means that the initial rate of dislocation generation, and hence the rate of initial work hardening, increases with increasing volume fraction of martensite. For comparison, see Figure 4. This also implies that $f_{1}$ controls the initial rate of energy absorption and hence the initial crashworthiness of the material.

It is worth to notice that not all the available ferrite has been plastically deformed at necking, see Figure 11, which also is in accordance with the experimental observations, compare Figure 3. This relative amount of undeformed ferrite, see red circles in Figure 11, increases with increasing $f_{m}$, or decreasing $f_{0}$. Consequently, the material does not use all its "potential" before necking occurs. This tendency increases with increasing $f_{m}$. The fact that the rate constant $r$ remains almost independent of $f_{m}$ suggests that the

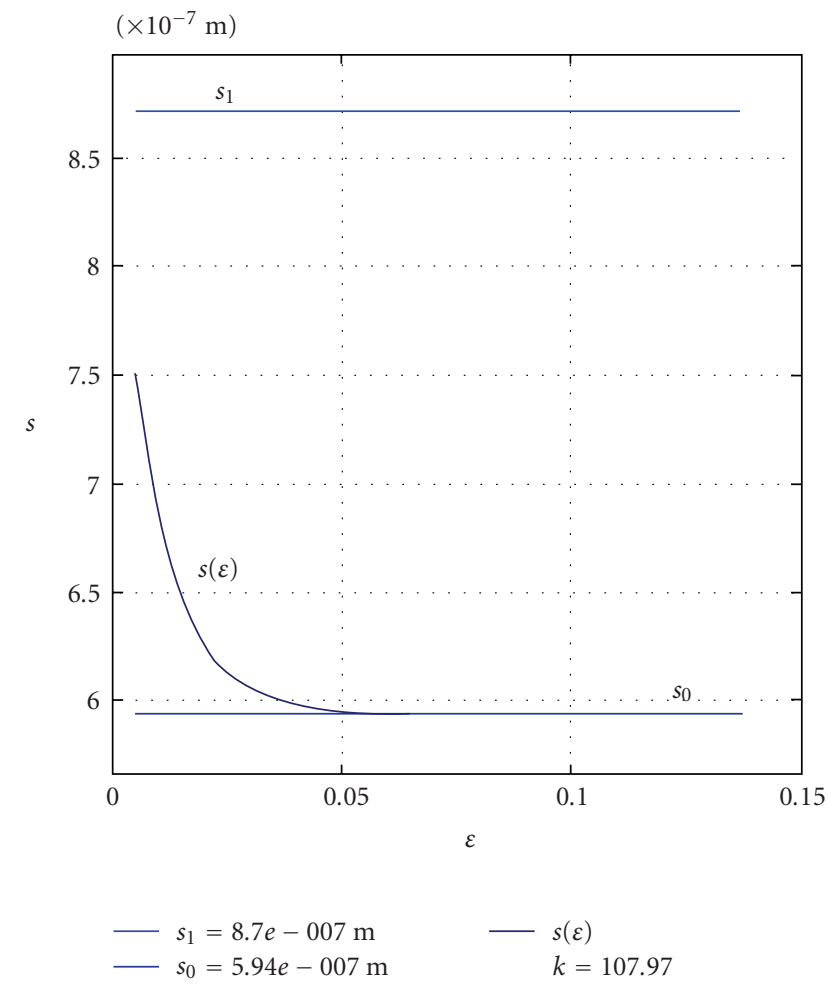

Figure 9: DP500 (B3): mobile dislocation mean free path $s(\varepsilon)$, starting from an initial value $s_{1}$, decreasing to $s_{0}$.

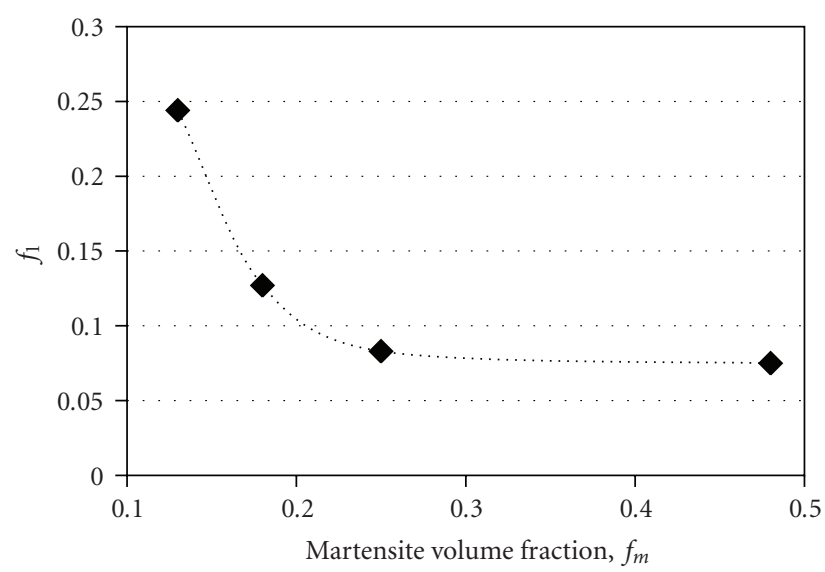

FIGURE 10: Initial active volume fraction of ferrite (vol\%), $f_{1}$, versus martensite volume fraction. 

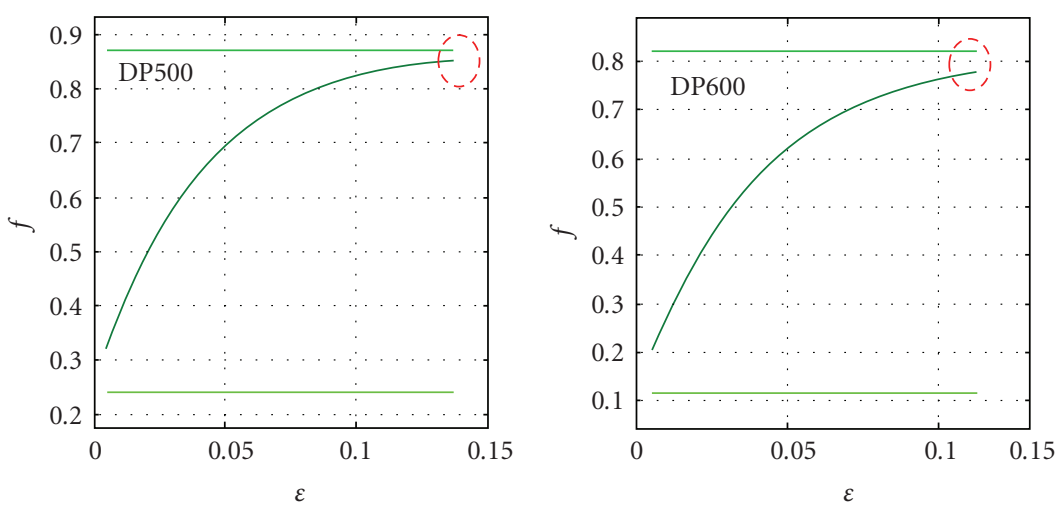

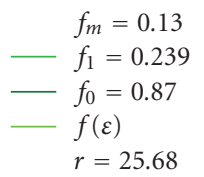

(a)

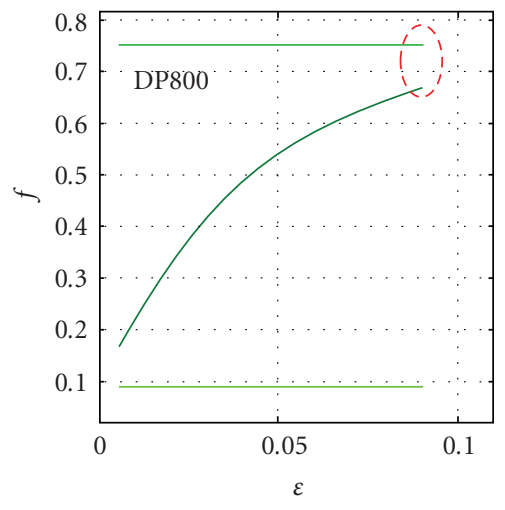

$$
f_{m}=0.25
$$

$-f_{1}=0.088$

$-f_{0}=0.75$

$-f(\varepsilon)$

$r=22.84$

(c)

$$
\begin{aligned}
& f_{m}=0.18 \\
- & f_{1}=0.114 \\
- & f_{0}=0.82 \\
- & f(\varepsilon) \\
& r=24.88
\end{aligned}
$$

(b)

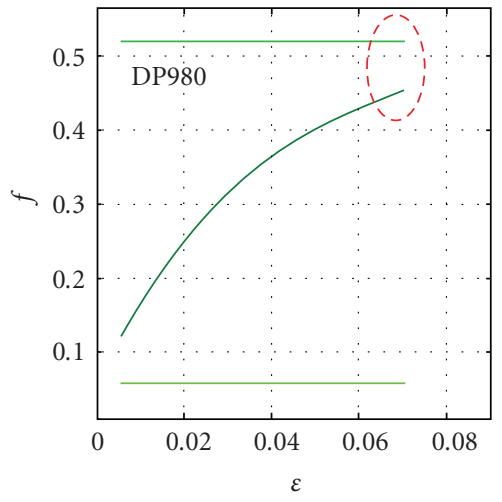

$$
\begin{array}{ll} 
& f_{m}=0.48 \\
- & f_{1}=0.057 \\
- & f_{0}=0.52 \\
- & f(\varepsilon) \\
& r=27.3
\end{array}
$$

(d)

FIGURE 11: $f(\varepsilon)$ for all grades. The relative amount of undeformed ferrite, indicated by rings, increases as $f_{m}$ increases.

resistance to the propagation of the plastic deformation fronts is only marginally dependent on steel grade.

4.6.2. The Initial and Final Mean Free Paths $s_{1}$ and $s_{0}$ and the Rate Constant $k$. As stated above, is it assumed that the plastic deformation takes place solely in the ferrite phase. In the ferrite, the mean free path of dislocation motion, $s(\varepsilon)$, starts from a value $s_{1}$ and transcends to a final value, $s_{0}$, see Figure 9. In Figure 12, $s_{0}$ is plotted versus $f_{m}$ for the steel grades under investigation here, and the graph shows that $s_{0}$ diminishes with increasing martensite content. This is well in line with the observed increase in deformation hardening rate with increasing $f_{m}$ : the smaller the dislocation mean free path the larger the hardening.

Hence both $f_{1}$ and $s_{0}$ are contributing to an enhanced rate of work hardening; $f_{1}$ dominates in the initial stages while $s_{0}$ dominates at higher levels of strain. There are reasons to believe that the initial mean free path of dislocation motion, $s_{1}$, may be influenced by the residual stresses close to the martensite particles as well as by the compatibility condition, and may therefore suffer from some uncertainty. This is also indicated by the results in Table 5 .

4.6.3. The Friction Stress, $\sigma_{i 0}$, and Its Components. The friction stress, $\sigma_{i 0}$, in the Taylor equation (1) consists of the following hardening components:

$$
\sigma_{i 0}=\sigma_{g}+\sigma_{p}+\sigma_{s}+\sigma^{*}
$$

where $\sigma_{g}$ is grain size hardening, $\sigma_{p}$ is precipitation hardening, $\sigma_{s}$ solution hardening, and $\sigma^{*}$ is thermal hardening.

In Figure 13, the values of the friction stress obtained in the fitting procedure (see Table 5), are plotted versus the 


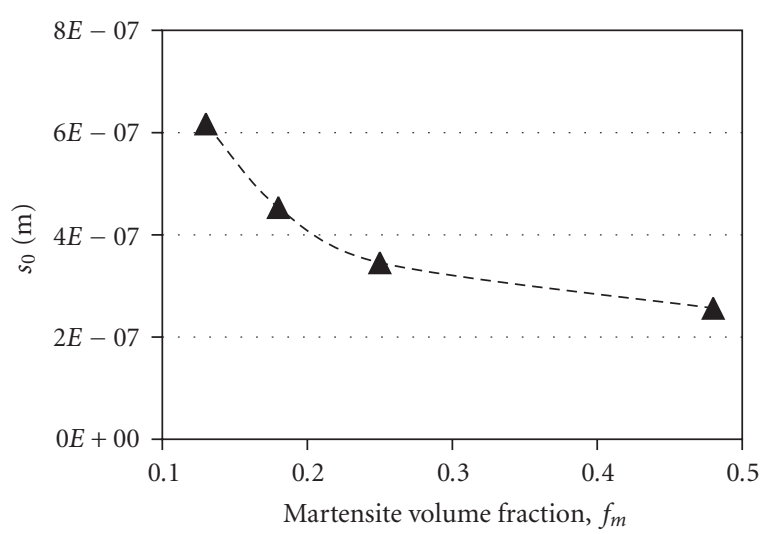

FIGURE 12: Final dislocation mean free path, $s_{0}$, versus martensite volume fraction, $f_{m}$.

volume fraction of martensite. It is obvious that there is a strong linear relationship $\left(R^{2} \sim 97 \%\right)$ between $\sigma_{i 0}$ and $f_{m}$ indicating that there might be some type of particle hardening or solution hardening mechanism in operation. In Section 5.3 it will be shown that $\sigma_{i 0}$ is inversely proportional to the square root of the ferrite grain diameter, $d$, indicating that a Hall-Petch mechanism is in fact also involved. Although the local strain rate varies somewhat during tensile testing we will, as a first approximation, assume that the variations in $\sigma^{*}$ may be neglected due to the low strain rate applied.

4.6.4. The Strain at Necking, $\varepsilon_{n}$. The strain at necking, $\varepsilon_{n}$, is during the fitting procedure evaluated for each grade, using the criteria $d \sigma / d \varepsilon=\sigma$, and the values are in excellent agreement with the corresponding experimental ones. The impact of martensite content on strain to necking is plotted in Figure 14.

We can see that $\varepsilon_{n}$ decreases with increasing amount of martensite from a value of around $14 \%$ at $f_{m}=0.13$ to $8 \%$ at $f_{m}=0.48$. One important reason for this behavior is of course that the friction stress increases, see Figure 13. Another reason is that the decrease in $f_{1}$ gives rise to an initially high rate of dislocation generation and hence a smaller rate of deformation hardening at higher strains, that is, smaller $\varepsilon_{n}$-values. However, the fact that $s_{0}$ decreases with increasing $f_{m}$, see Figure 12, results in an increase of the rate of strain hardening and explains why the ductility still stays at a high level in spite of the high strength.

\section{Discussion}

It is well documented that (1) and (2) hold for singlephase materials, but there might be questions regarding their applicability to multiphase materials. In the present theory we have introduced the inhomogenity factor $f$ to take into account the effect of a hard second phase on the rate of dislocation generation, see (10). There might also be effects on the friction stress, $\sigma_{i 0}$, due to the load sharing between the various phases. One example is the banding structure

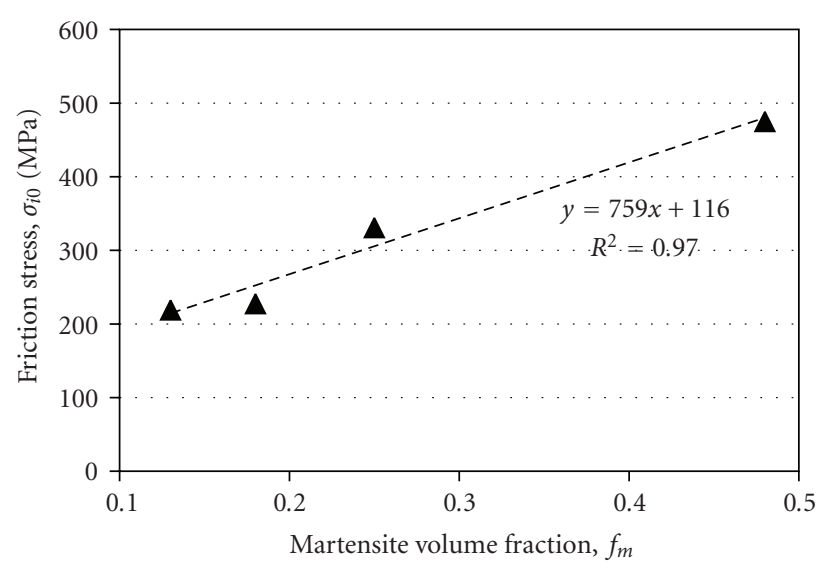

FIGURE 13: Friction stress versus martensite volume fraction.

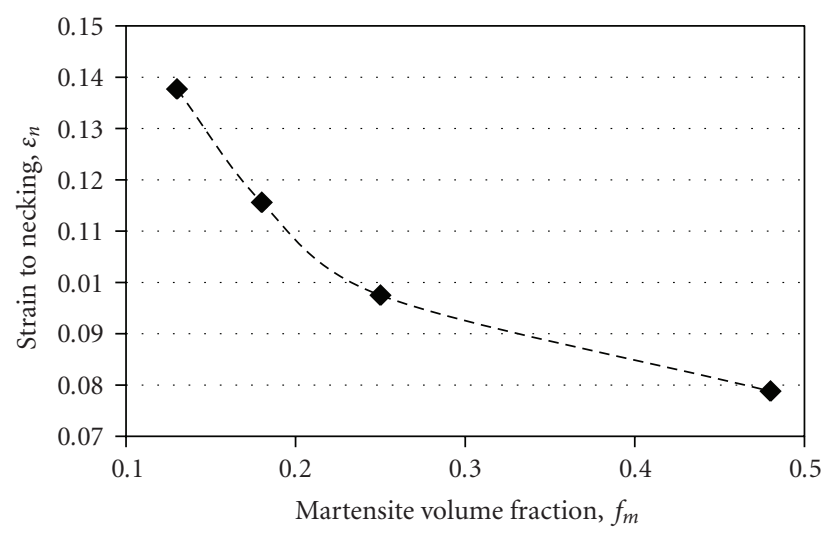

FIGURE 14: Strain to necking as function of martensite volume fraction.

occurring in DP steels. Another might be effects from the "skeleton structure" proposed by Liedl et al. [16]. However, we will assume that (1), in its present shape, holds for DP steel and we will deal with the above proposed possible effects in more detail in a coming paper.

5.1. General. As mentioned above, DP steels are characterized by high strength, good ductility, and excellent energy absorption. According to the present theory, these properties are determined by the volume fraction of martensite, $f_{m}$, the initial volume fraction of active ferrite, $f_{1}$, the final dislocation mean free path, $s_{0}$, and the friction stress, $\sigma_{i 0}$. We will also demonstrate that the ferrite grain diameter, $d$, plays an important role in this context.

We will now proceed by in detail to discuss how the volume fraction of martensite, $f_{m}$, the ferrite grain diameter, $d$, and the mean free path of dislocation motion, $s_{0}$, affect the friction stress, $\sigma_{i 0}$, the work hardening component, $\sigma_{\text {def }}(8 \%)$ and the total flow stress, $\sigma(8 \%)$ in the investigated DP steels.

5.2. Impact of $f_{m}$ on $\sigma_{i 0}, \sigma_{\mathrm{def}}(8 \%)$ and $\sigma(8 \%)$. According to Figure 5, YS and TS show a good linearity with $f_{m}$. A similar linearity seems to hold for the friction stress, $\sigma_{i 0}$, 
see Figure 13. In Figure 15, the true flow stress at $8 \%$ plastic strain, $\sigma(8 \%)$, the true deformation hardening component at $8 \%$ plastic strain, $\sigma_{\text {def }}(8 \%)$, and the friction stress, $\sigma_{i 0}$, are plotted versus $f_{m}$.

It is apparent that both $\sigma_{i 0}$ and $\sigma(8 \%)$ display a good linearity to $f_{m}$ with $R^{2}$-values in the range $96 \%-97 \%$. The linearity between $\sigma_{\text {def }}(8 \%)$ and $f_{m}$ is, however, less pronounced with a $R^{2} \approx 92 \%$. The good linearity between $\sigma(8 \%)$ and $f_{m}$ might therefore be a result of the fact that $\sigma(8 \%)$ is the sum of $\sigma_{i 0}$ and $\sigma_{\text {def }}(8 \%)$ and that it is $\sigma_{i 0}$ that accounts for the enhanced linearity.

To exemplify the generality of the obtained results, a plot similar to that presented in Figure 15 but with added flow stress data at the strains $0.2 \%, 1 \%, 3 \%$ and $5 \%$, is presented, see Figure 16. It is evident that the linearity between the flow stress, $\sigma(\varepsilon)$, and $f_{m}$ holds for all strains.

If we now plot $\sigma_{i 0}, \sigma_{\mathrm{def}}(8 \%)$ and $\sigma(8 \%)$ versus $f_{m}{ }^{-1 / 2}$, the results depicted in Figure 17 are obtained. These results indicate a well-defined linearity between $\sigma_{\text {def }}(8 \%)$ and $f_{m}{ }^{-1 / 2}$ with $R^{2} \sim 1$, a somewhat less good linearity between $\sigma(8 \%)$ and $f_{m}{ }^{-1 / 2}$ with $R^{2} \sim 0.98$ and a relatively poor linearity between $\sigma_{i 0}$ and $f_{m}{ }^{-1 / 2}$ with $R^{2} \sim 0.92$. Based on the results in Figure 16 and Figure 17 we may conclude that the friction stress $\sigma_{i 0}$ is linearly related to $f_{m}$ while the work hardening component of the flow stress, $\sigma_{\text {def }}(8 \%)$, varies with martensite content as $f_{m}{ }^{-1 / 2}$.

5.3. Impact of the Ferrite Grain Diameter, $d$, on $\sigma_{i 0}, \sigma_{\operatorname{def}}(8 \%)$, and $\sigma(8 \%)$. The Hall-Petch relation $[22,23]$ is well known and frequently used to describe the grain size dependences of the friction stress, $\sigma_{i 0}$, and the flow stress $\sigma_{f}(\varepsilon)$ of metals, that is,

$$
\begin{gathered}
\sigma_{i 0}=\sigma_{0 i}+k_{i} \cdot d^{-1 / 2}, \\
\sigma_{f}(\varepsilon)=\sigma_{0 f}(\varepsilon)+k_{f} \cdot d^{-1 / 2}
\end{gathered}
$$

where $\sigma_{0 i}$ and $\sigma_{0 f}$ are "friction stresses" and $k_{i}$ and $k_{f}$ are constants. We will now compare some experimental results obtained from single-phase ferrite with results from the DP steels in this study.

The following results for the flow stresses at 5.8\%, 9.5\% and $19.9 \%$ plastic strain were obtained from an Orkla-iron [19]:

$$
\begin{aligned}
& \sigma_{f}(0.058)=123+0.4 \cdot d^{-1 / 2}, \\
& \sigma_{f}(0.095)=162+0.4 \cdot d^{-1 / 2}, \\
& \sigma_{f}(0.199)=212+0.4 \cdot d^{-1 / 2}
\end{aligned}
$$

For the same Orkla-iron the following expression for the friction stress $\sigma_{i 0}$ was obtained:

$$
\sigma_{i 0}=-47+0.4 \cdot d^{-1 / 2} .
$$

These relationships are typical for single-phase ferrite and since $k_{f}=k_{i}=0.4$, see (13a) $-(13 \mathrm{~d})$, the results indicate that the grain size dependence of the flow stress is emanating from the friction stress. It also means that the strain hardening

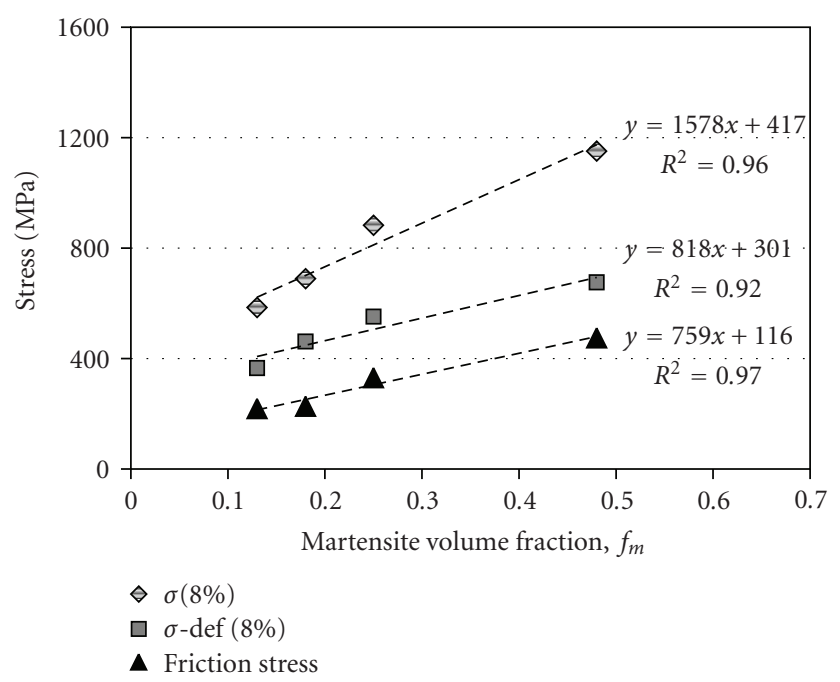

FIGURE 15: Friction stress, $\sigma_{i 0}$, the work hardening component, $\sigma_{\text {def }}$ $(8 \%)$ and flow stress at $8 \%$ plastic strain, $\sigma(8 \%)$ versus martensite volume fraction, $f_{m}$.

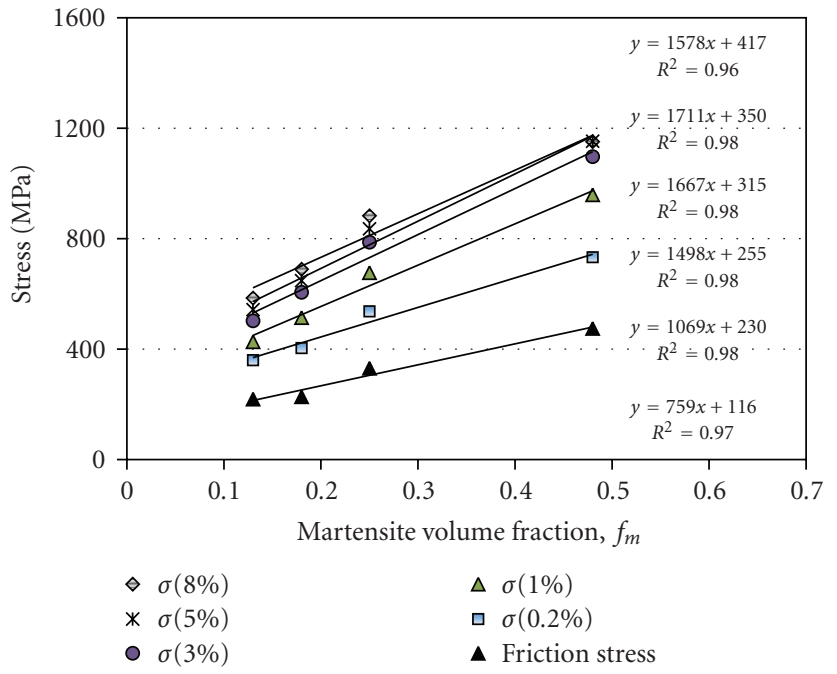

FIGURE 16: Flow stress at different strains versus $f_{m}$.

flow stress component, $\sigma_{\mathrm{def}}(\varepsilon)$, in single-phase ferrite is grain size independent which is in accordance with other experimental observations [19].

Concerning the DP steels, the results indicate quite a different behavior of the flow stresses, see Figure 18. The total flow stress, $\sigma_{f}(8 \%)$, the work hardening component, $\sigma_{\text {def }}(\varepsilon)$, and the friction stress, $\sigma_{i 0}$, are plotted versus $d^{-1 / 2}$ and the following linear relationships are obtained:

$$
\begin{gathered}
\sigma_{f}(0.08)=2.76 \cdot d^{-1 / 2}-261, \\
\sigma_{\text {def }}(0.08)=1.46 \cdot d^{-1 / 2}-60, \\
\sigma_{i 0}=1.30 \cdot d^{-1 / 2}-201 .
\end{gathered}
$$

We can see that the Hall-Petch constant, $k_{f}$, for the total flow stress, $\sigma_{f}(8 \%)$, attains the value of 2.76 , see (14a), while 


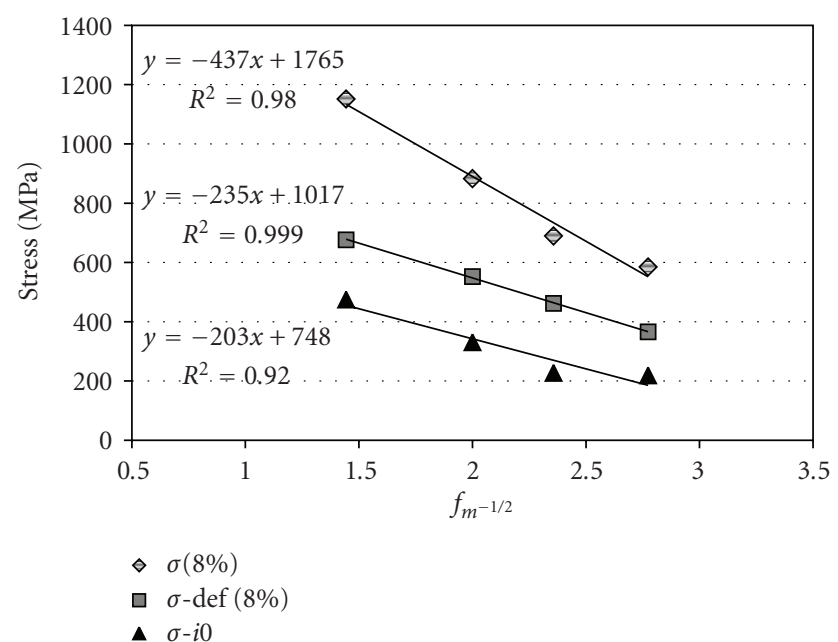

Figure 17: Flow stress at different strains versus $f_{m}{ }^{-1 / 2}$.

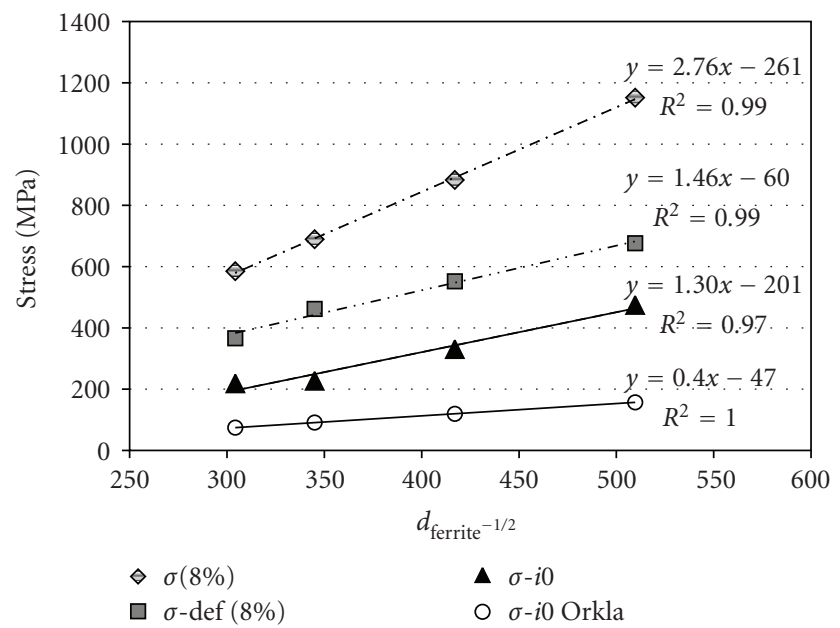

FIGURE 18: Flow stress at different strains versus $d_{\text {ferrite }}{ }^{-1 / 2}$.

the corresponding value for the Orkla-iron is 0.4 , see (13a). Hence, the $k_{f}$-value for the DP steels is a factor of $\sim 7$ larger than that in the Orkla-iron. This means that the grain size sensitivity for DP steels is about 7 times larger than that for single-phase ferrite. This type of Hall-Petch relation in DP-steel is also found by Jiang et al. [9], who studied the correlation between flow stress and ferrite grain size in DP steels with varying martensite content.

It should also be noticed that the work hardening component, $\sigma_{\text {def }}(8 \%)$, is grain size dependent with a $k_{\text {def }}-$ value of 1.46 , see $(14 \mathrm{~b})$. This is most interesting since the $k_{\mathrm{def}}$ -value for Orkla-iron is zero. $\left(k_{f}=k_{i}+k_{\text {def }}\right.$, where $k_{\text {def }}$ is the Hall-Petch coefficient for the work hardening component.) A possible explanation to this grain size dependence of $\sigma_{\text {def }}(\varepsilon)$ in the DP steels is that the martensite particles, by agglomerating in the ferrite grain boundaries, make it more difficult for the plastic deformation process to propagate from grain to grain. The friction stress also exhibits a pronounced grain size dependence, see (14c), with a $k_{i}$-value of 1.30 which is approximately 3.3 times larger than in singlephase ferrite.

Now, if these observations have a broader universality, it indicates that the ferrite grain size, together with the martensite distribution along the grain boundaries, may be factors to consider when improving the strength and the ductility of DP steels.

For a deeper analysis of the results presented above we must correlate the Hall-Petch equations (12a)-(14c) with the terminology of the present model. This is described as follows;

If we put $\sigma_{g}=k_{i} \cdot d^{-1 / 2}$ and $\sigma_{0}=\sigma_{p}+\sigma_{s}+\sigma^{*}$, the friction stress $\sigma_{i 0}$, see (11), may be rewritten in the following HallPetch form:

$$
\sigma_{i 0}=\sigma_{0}+k_{i} \cdot d^{-1 / 2}
$$

where $k_{i}$ is a constant and $d$ is the ferrite grain diameter.

Proceeding from (1), the flow stress $\sigma(\varepsilon)$ may now be written

$$
\sigma(\varepsilon)=\sigma_{\mathrm{def}}(\varepsilon)+\sigma_{0}+k_{i} \cdot d^{-1 / 2} .
$$

It is necessary to figure out how it is possible that the work hardening part, $\sigma_{\text {def }}(\varepsilon)$, exhibits a $d^{-1 / 2}$-dependence. Analyzing the experimental data as well as the values of the theoretical parameters obtained in the fitting procedure, it has become clear that there exist correlations between the experimental parameters and the theoretical ones. In Figure 19, the relation between the dislocation mean free path, $s_{0}$ and the ferrite grain size is presented and we can see that $s_{0}$ is linearly related to $d$ in accordance with (16)

$$
s_{0}=0.051 \cdot d+5 \cdot 10^{-8}[\mathrm{~m}] .
$$

This means that $s \infty s_{0} \infty d$ at high levels of strain and since we, according to (1), need to take the square root of $\rho(\varepsilon)$ to obtain the flow stress, we have an approximate $d^{-1 / 2}$-factor related to the work hardening component.

What is observed is thus a "Hall-Petch like" relationship in DP steels showing that the $k$-value for the friction stress is higher than the one for Orkla iron. We have also observed that the work hardening component, $\sigma_{\text {def }}$, exhibits a "HallPetch like" behavior with high $k$-values, which is most interesting. Adding these two effects results in a total $k$ value being 7 times higher than that for Orkla iron. It is quite evident that it is the presence of martensite and the inhomogeneous deformation in the DP steel that cause this behavior. The exact physical mechanism behind the behavior is however still unidentified.

5.4. Impact of the Dislocation Mean Free Path, $s_{0}$, on $\sigma_{i 0}$, $\sigma_{\text {def }}(8 \%)$ and $\sigma(8 \%)$. In Figure 20 the work hardening component $\sigma_{\text {def }}(8 \%)$, and the flow stress $\sigma(8 \%)$, are plotted versus $s_{0}{ }^{-1 / 2}$, and it is obvious that a good linearity with a $R^{2}=0.99$ is obtained for $\sigma_{\text {def }}(8 \%)$. In the same figure the friction stress, $\sigma_{i 0}$, is also plotted, but in this case the linearity is less pronounced with $R^{2}=0.92$. Since $\sigma(8 \%)$ is the sum of $\sigma_{\text {def }}(8 \%)$ and $\sigma_{i 0}$ (see $\left.(1)\right)$, it is not surprising that 


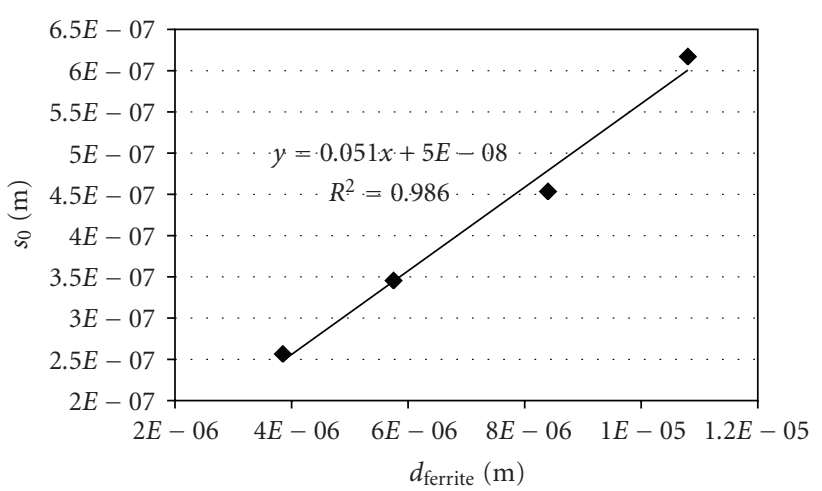

FIGURE 19: Linear relation between $s_{0}$ and $d_{\text {ferrite }}$.

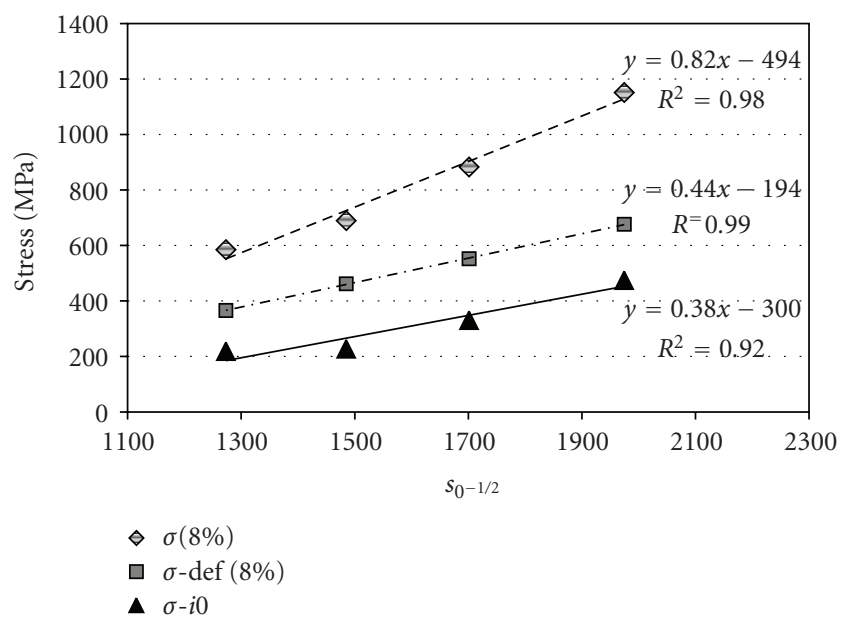

Figure 20: Flow stress at $8 \%$ strain, deformation work hardening part at $8 \%$ strain and friction stress versus dislocation mean free path, $s_{0}$.

$\sigma(8 \%)$ also exhibits a somewhat less distinct linearity $\left(R^{2}=\right.$ $0.98)$. Therefore a realistic and also physically acceptable assumption is that the work hardening component is, but the friction stress is not, $s_{0}^{-1 / 2}$-dependent.

5.5. Relationships between $f_{m}, f_{1}, d$ and $s_{0}-A n$ Analysis. The results presented above show that the work hardening component, $\sigma_{\text {def }}(\varepsilon)$, of the flow stress $\sigma(\varepsilon)$ is proportional to $f_{m}{ }^{-1 / 2}, d^{-1 / 2}$ and $s_{0}{ }^{-1 / 2}$. It is therefore reasonable to assume that there must be some kind of correlation between these three parameters. Since the initial active volume fraction $f_{1}$ has a distinct influence on the initial rate of work hardening it is reasonable to assume that this parameter is also related to one or more of the above mentioned parameters. An analysis has shown that this is in fact the case. Since such an analysis lies outside the scope of this paper we will present these results in a planned report.

\section{Conclusions}

The present dislocation theory accurately describes the plastic deformation behavior of four-dual-phase steel grades with martensite contents of $13,18,25$, and $48 \%$, respectively. Results from microstructure investigations as well as results from analyses of the stress-strain behavior in terms of the present theory, tell us that the plastic deformation process in DP-steel is inhomogeneous. By introducing the concept of a non-homogeneity parameter $f(\varepsilon)$, that specifies the volume fraction of ferrite that takes active part in the plastic deformation process, it is possible to give a precise physical description of the deformation behavior until necking.

The impact of the volume fraction of martensite on the plastic deformation of DP steels is significant. The larger the martensite content the smaller the initial volume fraction of ferrite taking an active part in the deformation process, which in turn yields a higher initial deformation hardening rate. This explains the high energy absorbing capacity of DP steels with high volume fractions of martensite. It is also observed, both experimentally and theoretically, that some volume of the ferrite fraction does not take part at all in the plastic deformation, at least for strains up to necking.

The effect of ferrite grain size strengthening in DP-steel is important. The flow stress grain size sensitivity for DP steels is observed to be 7 times larger than that for single phase ferrite. There is also a strong correlation between the dislocation mean free path and the ferrite grain size. Further, it is observed that the work hardening component of the flow stress shows a strong ferrite grain size dependence which is in glaring contrast to the behavior of ferritic steels.

The results point to that the ferrite grain size, together with the martensite distribution along the grain boundaries, are important factors to consider when improving the strength and the ductility of DP steels.

\section{Acknowledgments}

The authors would like to thank Professor Göran Engberg at Dalarna University and Professor John Ågren at Royal Institute of Technology for support and stimulating discussions, Lena Ryde at Swerea KIMAB for valuable EBSD analyses. Thanks also to all collaborators at SSAB for support and encouragement. For financial support SSAB, the Swedish Knowledge Foundation and the Swedish Steel Producers Association are acknowledged.

\section{References}

[1] C. Federici, S. Maggi, and S. Rigoni, The Use of Advanced High Strength Steel Sheets in the Automotive Industry, Fiat AutoEngineering \& Design, Turin, Italy, 2005.

[2] J. R. Fekete, J. N. Hall, D. J. Meuleman, and M. Rupp, "Progress in implementation of advanced high-strength steels into vehicle structures," Iron \& Steel Technology, vol. 5, no. 10, pp. 55-64, 2008.

[3] R. Koehr, ULSAB-AVC Advenced Vehicle Concepts Overview Report, in Safe, Affordable, Fuel Efficient Vehicle Concepts for the 21st Century Designed in Steel, Porsche Engineering Services, Detroit, Mich, USA, 2002.

[4] P. Tsipouridis, E. Werner, C. Krempaszky, and E. Tragl, "Formability of high strength dual-phase steels," Steel Research International, vol. 77, no. 9-10, pp. 654-667, 2006. 
[5] M. Takahashi, "Development of high strength steels for automobiles," Nippon Steel Technical Report, no. 88, pp. 2-7, 2003.

[6] J. Bouquerel, K. Verbeken, and B. C. De Cooman, "Microstructure-based model for the static mechanical behaviour of multiphase steels," Acta Materialia, vol. 54, no. 6, pp. 1443-1456, 2006.

[7] V. Colla, M. De Sanctis, A. Dimatteo, G. Lovicu, A. Solina, and R. Valentini, "Strain hardening behavior of dual-phase steels," Metallurgical and Materials Transactions A, vol. 40, no. 11, pp. 2557-2567, 2009.

[8] Z. H. Cong, N. Jia, X. Sun, Y. Ren, J. Almer, and Y. D. Wang, "Stress and strain partitioning of ferrite and martensite during deformation," Metallurgical and Materials Transactions A, vol. 40, no. 6, pp. 1383-1387, 2009.

[9] Z. Jiang, Z. Guan, and J. Lian, "Effects of microstructural variables on the deformation behaviour of dual-phase steel," Materials Science and Engineering A, vol. 190, no. 1-2, pp. 5564, 1995.

[10] C. Kim, "Modeling tensile deformation of dual-phase steel," Metallurgical Transactions A, vol. 19, no. 5, pp. 1263-1268, 1988.

[11] M. F. Ashby, "The deformation of plastically nonhomogeneous alloys," in Strengthening Method in Crystals, A. Kelly and B. Nicholson, Eds., Applied Science Publishers LTD, London, UK, 1971.

[12] H. Mughrabi, "Dual role of deformation-induced geometrically necessary dislocations with respect to lattice plane misorientations and/or long-range internal stresses," Acta Materialia, vol. 54, no. 13, pp. 3417-3427, 2006.

[13] H. Mughrabi, "On the current understanding of strain gradient plasticity," Materials Science and Engineering A, vol. 387-389, no. 1-2, pp. 209-213, 2004.

[14] D. A. Korzekwa, D. K. Matlock, and G. Krauss, "Dislocation substructure as a function of strain in a dual-phase steel," Metallurgical Transactions A, vol. 15, no. 6, pp. 1221-1228, 1984.

[15] G. I. Taylor, "The mechanism of plastic deformation of crystals. Part I. Theoretical," Proceedings of the Royal Society A, vol. 145, pp. 362-387, 1934.

[16] U. Liedl, S. Traint, and E. A. Werner, "An unexpected feature of the stress-strain diagram of dual-phase steel," Computational Materials Science, vol. 25, no. 1-2, pp. 122-128, 2002.

[17] J. M. Rigsbee et al., "Structure-processing and structureproperty relations in commercially processed dual-phase steels," in Structure and Property of Dual-Phase Steels, R. A. Kot and J. W. Morrow, Eds., pp. 304-306, The Metallurgical Society of AIME, New Orleans, La, USA, 1979.

[18] Y. Bergström and Y. Granbom, A Dislocation Model for the Stress-Strain Behaviour of Dual-Phase Steel, International Deep Drawing Research Group, Oloftröm, Sweden, 2008.

[19] Y. Bergström, "The plastic deformation of metals-a dislocation model and its applicability," Reviews on Powder Metalurgy and Physical Ceramics, vol. 2, no. 2-3, pp. 79-265, 1983.

[20] G. Krauss, STEELS: Heat Treatment and Processing Principles, ASM International, 1989.

[21] A. R. Marder, "Deformation characteristics of dual-phase steels," Metallurgical Transactions A, vol. 13, no. 1, pp. 85-92, 1982.

[22] E. O. Hall, "The deformation and ageing of mild steel: III discussion of results," Proceedings of the Physical Society. Section B, vol. 64, no. 9, pp. 747-753, 1951.

[23] N. J. Petch, “The cleavage strength of polycrystals," The Journal of the Iron and Steel Institute, vol. 174, pp. 25-28, 1953. 

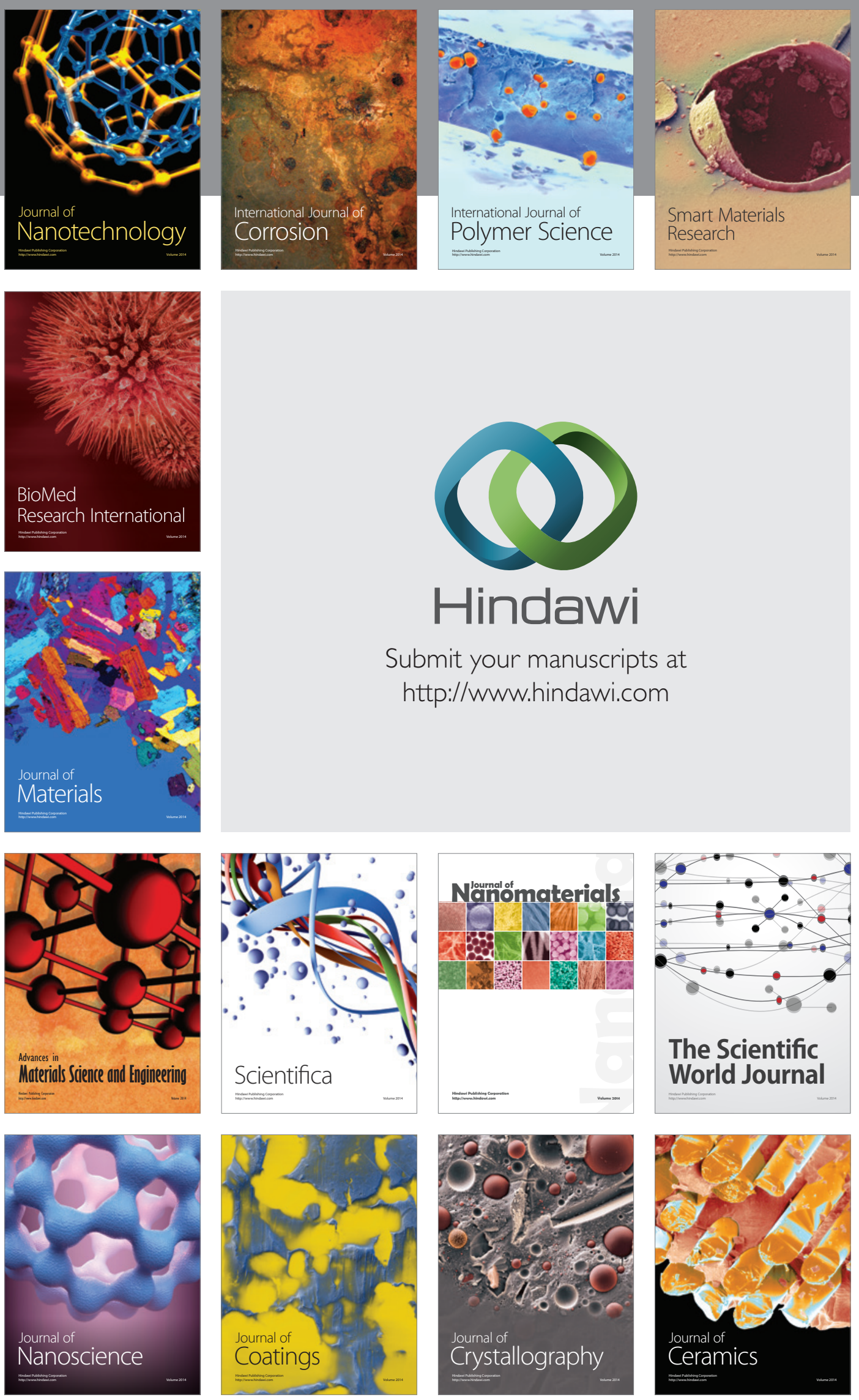

The Scientific World Journal

Submit your manuscripts at

http://www.hindawi.com

\section{World Journal}

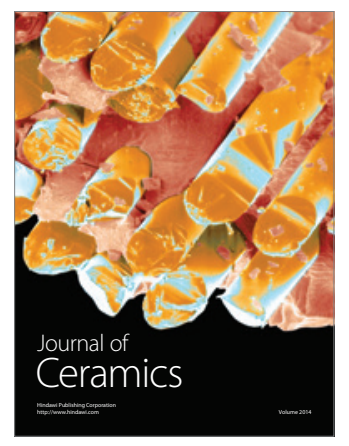

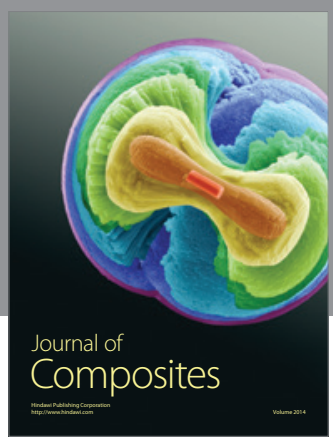
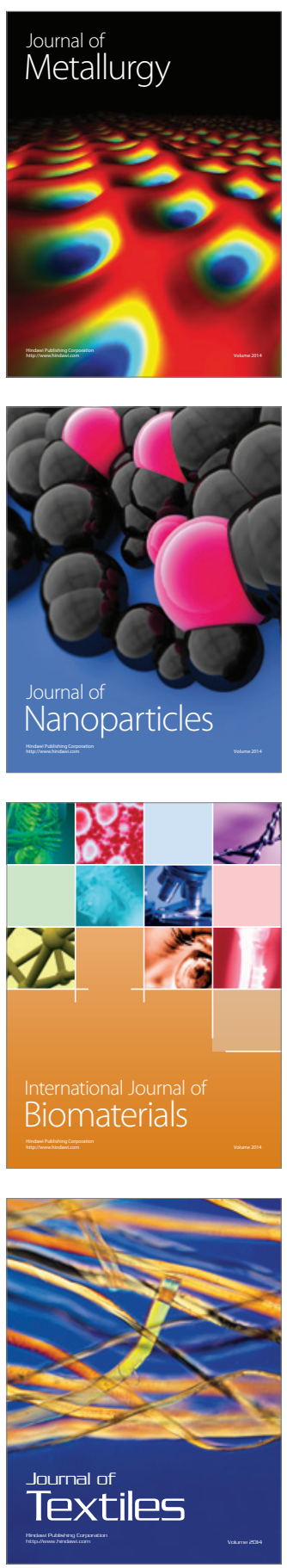